WSRC-TR-2002-00352

\title{
EROSION ANALYSIS FOR THE MISALIGNED U2 NOZZLE AND ITS CONNECTOR BLOCK
}

Si Young Lee and Richard A. Dimenna

Westinghouse Savannah River Company

Savannah River Site

Aiken, SC 29808

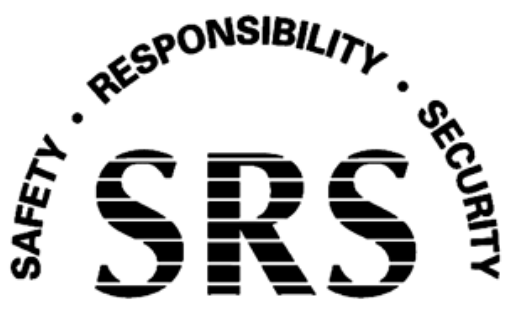

SAVANNAH RIVER SITE

Prepared for the U.S. Department of Energy under Contract No. DE-AC09-96SR18500 
This document was prepared in conjunction with work accomplished under Contract No. DE-AC09-96SR18500 with the U. S. Department of Energy.

\section{DISCLAIMER}

This report was prepared as an account of work sponsored by an agency of the United States Government. Neither the United States Government nor any agency thereof, nor any of their employees, makes any warranty, express or implied, or assumes any legal liability or responsibility for the accuracy, completeness, or usefulness of any information, apparatus, product or process disclosed, or represents that its use would not infringe privately owned rights. Reference herein to any specific commercial product, process or service by trade name, trademark, manufacturer, or otherwise does not necessarily constitute or imply its endorsement, recommendation, or favoring by the United States Government or any agency thereof. The views and opinions of authors expressed herein do not necessarily state or reflect those of the United States Government or any agency thereof.

This report has been reproduced directly from the best available copy.

Available for sale to the public, in paper, from: U.S. Department of Commerce, National Technical Information Service, 5285 Port Royal Road, Springfield, VA 22161, phone: (800) 553-6847, fax: (703) 605-6900

email: orders@ntis.fedworld.gov

online ordering: http://www.ntis.gov/help/index.asp

Available electronically at http://www.osti.gov/bridge

Available for a processing fee to U.S. Department of Energy and its contractors, in paper, from: U.S. Department of Energy, Office of Scientific and Technical Information, P.O. Box 62, Oak Ridge, TN 37831-0062,

phone: (865)576-8401,

fax: (865)576-5728

email: $\underline{\text { reports@ adonis.osti.gov }}$ 


\section{EROSION ANALYSIS FOR THE MISALIGNED U2 NOZZLE AND ITS CONNECTOR BLOCK}

SAVANNAH RIVER TECHNOLOGY CENTER

Si Young Lee and Richard A. Dimenna

August 2002

Westinghouse Savannah River Company

Savannah River Site

Aiken, SC 29808

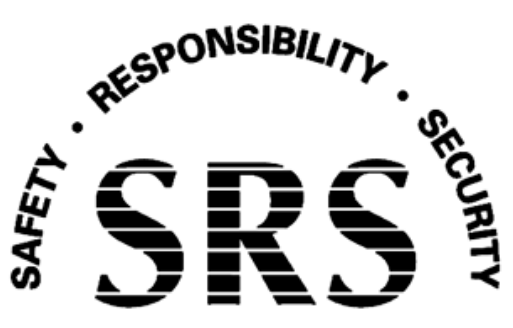

SAVANNAH RIVER SITE

Prepared for the U.S. Department of Energy under Contract No. DE-AC09-96SR18500

WSRC-TR-2002-00352 
(This Page Intentionally Left Blank) 
DOCUMENT:WSRC-TR-2002-00352

TITLE: EROSION ANALYSIS FOR THE MISALIGNED UL NOZZLE AND ITS CONNECTOR BLOCK

APPROVALS

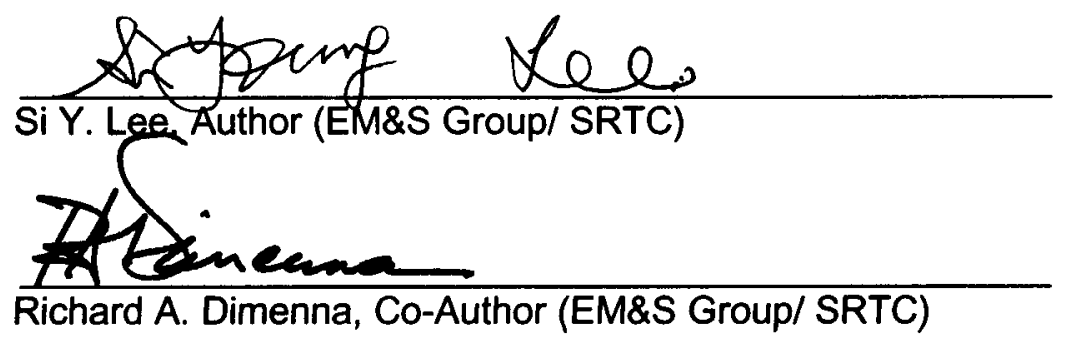

Mold Chapman

Noel F. Chapman, Customer Reviewer (CST Eng./HLWD)

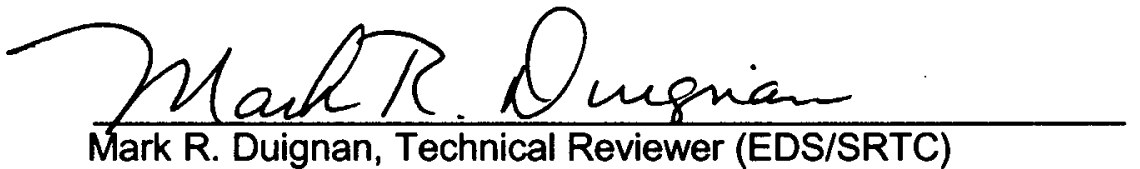

Mark R. Duignan, Technical Reviewer (EDS/SRTC)
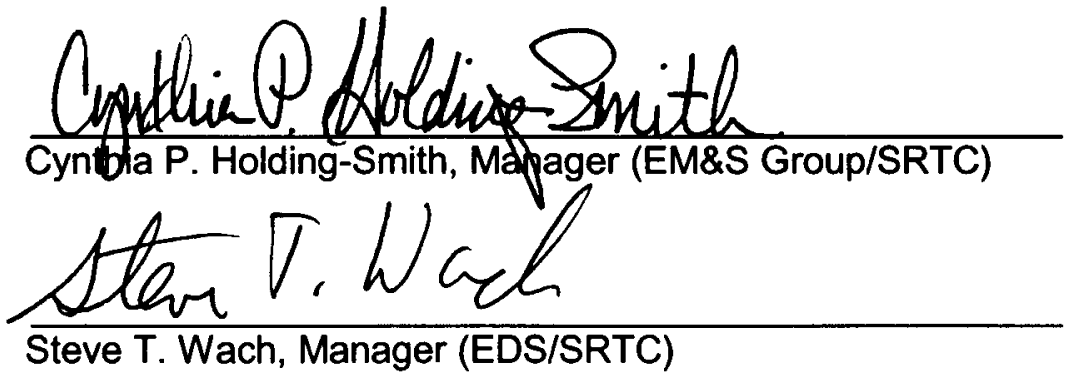

Date: $9-4-02$

Date: $9 \cdot 4 \cdot 02$

Date: $9 \cdot 10 \cdot 02$

Date: $9 / 4 / 2002$

Date: $9 / 12 / 02$

Date: $9 / 12 / 02$

-iii- 
WSRC-TR-2002-00352

(This Page Intentionally Left Blank) 
WSRC-TR-2002-00352

\section{Table of Contents}

List of Figures $\quad$ vii

$\begin{array}{ll}\text { List of Tables } & \text { ix }\end{array}$

Nomenclature $\quad$ xi

$\begin{array}{ll}\text { Abstract } & 1\end{array}$

Summary 2

1 Introduction 3

2. Analysis Approach and Methodology 7

2.1 Principal Mechanisms for the Present Analysis ............................................ 10

Wall Shear Stress .................................................................................... 11

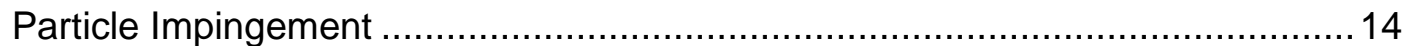

2.2 Computational Fluid Dynamics Methodology ................................................ 16

2.3 Modeling Boundary Selection for the CFD Model........................................ 17

3. Modeling Assumptions and Computational Domains 19

4. Results and Discussions 21

4.1 Benchmarking Results of the Present Model ..............................................21

4.2 Results of the Erosion Model for the Misaligned U2 Nozzle .............................28

5. Summary and Conclusions 51

6. References 53 
WSRC-TR-2002-00352

(This Page Intentionally Left Blank) 
WSRC-TR-2002-00352

\section{List of Figures}

Figure 1. Schematic of the $3 \mathrm{H}$ lift separator jumper system representing the misaligned U2 nozzle and its connector block for the present analysis.

Figure 2. Selection of modeling boundary and geometrical dimensions of computational domain as modeled for the present analysis.

Figure 3. Liquid entrainment mechanism for the steam injection under the misaligned U2 Nozzle and Its Connector.

Figure 4. Main driving mechanisms of erosion in a waste slurry flow for the present analysis.

Figure 5. Main mechanisms and methodology considered for the erosion analysis of the misaligned U2 nozzle and its connector block.

Figure 6. Computational domain and meshes of the three-dimensional model for the $3 \mathrm{H}$ evaporator lift jumper component with the misaligned U2 nozzle for the present analysis.

Figure 7. Test sections of the two elbows used in the slurry experiments [17].

Figure 8. Comparison of predictions with the test data available in the literature [17] using the standard $\kappa-\varepsilon$ turbulent model.

Figure 9. Erosion contour plot due to the particle impingement for horizontal pipe available in the literature [15] using standard $\kappa-\varepsilon$ turbulent model.

Figure 9a. Solid concentrations of slurry flow at the exit plane of the horizontal pipe available in the literature experiment [15] using a standard $\kappa-\varepsilon$ turbulent model.

Figure 10. Comparison of predictions with the erosion test data for horizontal pipe available in the literature [15] using the standard $\kappa-\varepsilon$ turbulent model with discrete solid phase.

Figure 11. Velocity and turbulence distributions at the center plane of the misaligned u2 nozzle component in a $3 \mathrm{H}$ evaporator steam lift system (The bottom side of the lift system shown above is fluid inlet.).

Figure 12. Pressure distributions at the center plane of the misaligned u2 nozzle component in a $3 \mathrm{H}$ evaporator steam lift system (The bottom side of the lift system shown above is fluid inlet.).

Figure 13. Velocity flow patterns at the mid-plane of the misaligned U2 nozzle

Figure 14. Velocity flow patterns at the mid-plane of the misaligned U2 nozzle in case of a smooth U2 nozzle connector

Figure 15. Radial velocity distributions at the cross-sectional planes of the upstream and downstream regions of the misaligned U2 nozzle.

Figure 16. Turbulence intensities at the cross-sectional planes of the upstream and downstream regions of the misaligned U2 nozzle.

Figure 17. Vorticity magnitudes at the cross-sectional planes of the upstream and downstream regions of the misaligned U2 nozzle.

Figure 18. Vorticity magnitude distributions at the vertical center plane of the misaligned U2 nozzle.

Figure 19. Wall shear stress distributions for a slurry flow driven by steam flow in $3 \mathrm{H}$ evaporator steam lift jumper.

Figure 20. Erosion mechanisms for the misaligned U2 nozzle mating surfaces due to the abrasive wall shear and particle impingement of waste droplets in a steam flow for $3 \mathrm{H}$ evaporator steam lift jumper. 
Figure 21. Particle trajectory and erosion distributions due to the impingement of waste droplets in a steam flow.

Figure 22. Erosion distributions due to the particle impingement of waste droplets driven by steam flow in $3 \mathrm{H}$ evaporator steam lift jumper...

Figure 23. Dispersed waste droplet distributions for a steam-driven flow......................... 45

Figure 24. Flow patterns for the upstream region of the misaligned U2 nozzle showing secondary flow circulation near the wall surface of nozzle connector block....... 46

Figure 25. Particle paths released from the mid-plane of the steam lift jumper near the upstream region of the misaligned U2 nozzle showing particle impingements on the misaligned horizontal surface due to the secondary flow circulation.

Figure 26. Flow patterns associated with particle impingement of waste droplets for $3 \mathrm{H}$ evaporator lift jumper with misaligned U2 nozzle.

Figure 27. Potential abrasive erosion locations near the misaligned U2 nozzle of $3 \mathrm{H}$ evaporator steam lift jumper system due to the wall shear stress.

Figure 28. Potential erosion locations near the misaligned $\mathrm{U} 2$ nozzle of $3 \mathrm{H}$ evaporator steam lift jumper system due to the impingement of waste droplets in a steam flow. 


\section{List of Tables}

Table 1. Design and operating conditions of the $3 \mathrm{H}$ evaporator steam injection system used in the present analysis

Table 2. Reference modeling conditions used for the present calculations

Table 3. Entrainment velocity to initiate the particle movement and average flow velocity for the reference conditions provided by Table 2

Table 4. Primary purposes of the CFD models used in the present analysis.

Table 5. Test conditions for the pressure drop measurements across the elbows

Table 6. Test conditions of the literature data [15] used in the present benchmarking of the present erosion model.

Table 7. Maximum shear stresses and relative maximum erosion rates for the upstream and downstream regions of the misaligned U2 nozzle under the reference conditions

Table 8. Maximum shear stresses and relative maximum erosion rates on the misaligned mating surfaces for the two different radial offset sizes created by the U2 nozzle misalignment.

Table 9. Maximum shear stresses and relative maximum erosion rates on the misaligned mating surfaces of the misaligned U2 nozzle mating surfaces for the two different designs of U2 nozzle connector..... 
WSRC-TR-2002-00352

(This Page Intentionally Left Blank) 
WSRC-TR-2002-00352

\section{Nomenclature}

$\mathrm{A}=\operatorname{area}\left(\mathrm{ft}^{2}\right.$ or $\left.\mathrm{m}^{2}\right)$

$\mathrm{C}=$ solid volume concentrations in slurry (--)

$\mathrm{C}_{\mathrm{p}}=$ specific heat $(\mathrm{J} / \mathrm{kg} \mathrm{K})$

$\mathrm{d}=$ branch diameter or solid particle size in slurry (ft or $\mathrm{m}$ )

$\mathrm{D}=$ main pipe diameter (ft or $\mathrm{m}$ )

$\mathrm{f}=$ empirical factor

$\mathrm{F}=$ force $(\mathrm{N})$

$\mathrm{g}=$ gravity $\left(\mathrm{m} / \mathrm{sec}^{2}\right)$

$\mathrm{I}=$ turbulence intensity (--)

$\mathrm{k}=$ constant in eq. (2) (--), or thermal conductivity $(\mathrm{W} / \mathrm{m} \mathrm{K})$

$\mathrm{m}=$ particle mass flowrate $(\mathrm{kg} / \mathrm{sec})$

$\mathrm{P}=$ pressure $(\mathrm{Pa})$

$\operatorname{Pr}=$ Prandtl number, $\mu \mathrm{C}_{\mathrm{p}} / \mathrm{k},(--)$

$\mathrm{R}=$ curvature radius of elbow or droplet radius ( $\mathrm{ft}$ or $\mathrm{m}$ )

$\mathrm{Re}=$ Reynolds number, $\mathrm{d} \rho \mathrm{u} / \mu$ or $\mathrm{d} \rho \mathrm{U} / \mu$

$\mathrm{t}=$ time (second)

$\mathrm{U}=$ slurry velocity $(\mathrm{ft} / \mathrm{sec}$ or $\mathrm{m} / \mathrm{sec})$

$\mathrm{u}=$ component velocity in $\mathrm{x}$-direction (ft/sec or $\mathrm{m} / \mathrm{sec}$ )

$\mathrm{u}^{\prime}=$ local turbulent velocity fluctuation in $\mathrm{x}$-direction (ft/sec or $\mathrm{m} / \mathrm{sec}$ )

$\mathrm{v}=$ local flow velocity or component velocity in $\mathrm{y}$-direction (ft/sec or $\mathrm{m} / \mathrm{sec}$ )

$v^{\prime}=$ local turbulent velocity fluctuation in $y$-direction ( $\mathrm{ft} / \mathrm{sec}$ or $\mathrm{m} / \mathrm{sec}$ )

$\mathrm{V}=$ average velocity magnitude ( $\mathrm{ft} / \mathrm{sec}$ or $\mathrm{m} / \mathrm{sec}$ )

$\mathrm{W}=$ weight fraction of solids in slurry (--)

$\mathrm{w}=$ component velocity in $\mathrm{z}$-direction $(\mathrm{ft} / \mathrm{sec}$ or $\mathrm{m} / \mathrm{sec}$ )

$w^{\prime}=$ local turbulent velocity fluctuation in z-direction (ft/sec or $\mathrm{m} / \mathrm{sec}$ )

$\mathrm{x}=$ local position along the $\mathrm{x}$-direction under Cartesian coordinate system (ft or $\mathrm{m}$ )

$\mathrm{y}=$ local position along the $\mathrm{y}$-direction under Cartesian coordinate system (ft or $\mathrm{m}$ )

$\mathrm{z}=$ local position along the $\mathrm{y}$-direction under Cartesian coordinate system (ft or $\mathrm{m}$ ) 


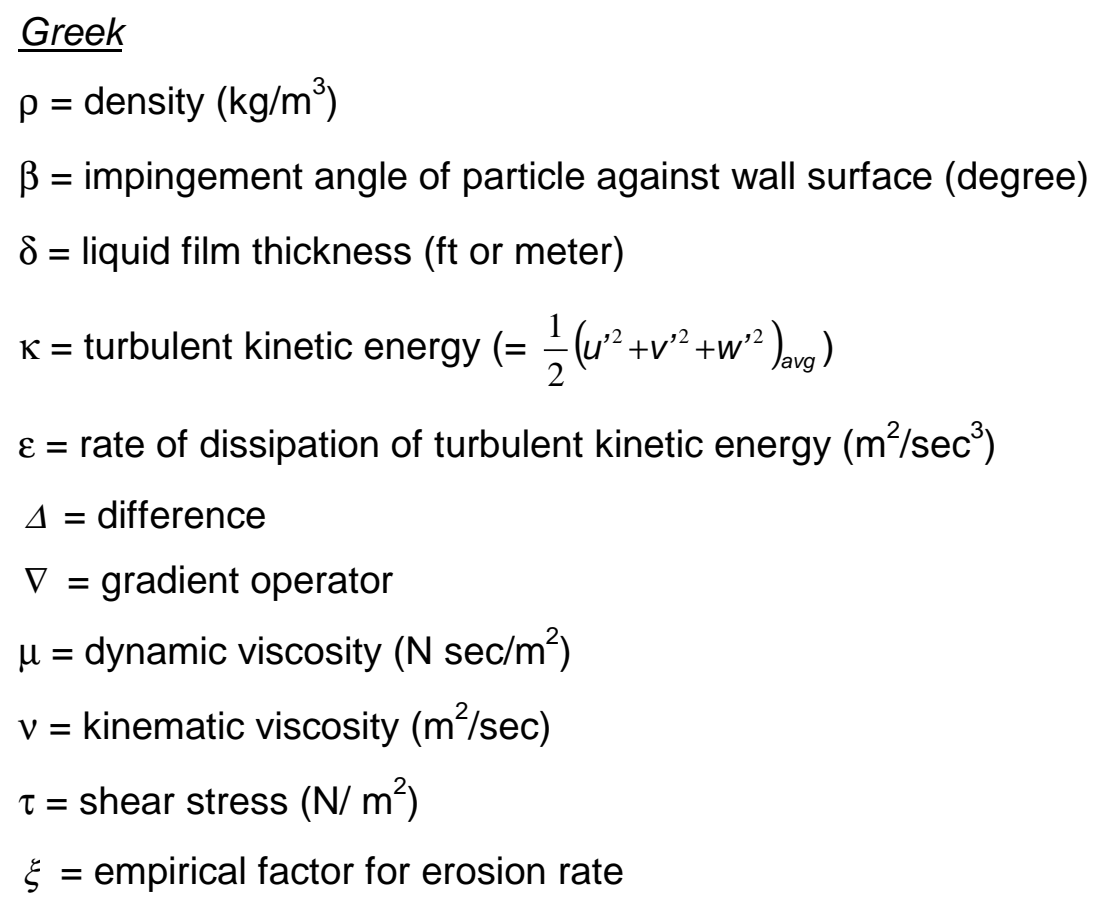

Subscript

avg = average

$\mathrm{C}=$ critical

$\mathrm{d}=$ incident particle

droplet $=$ liquid droplet

$\mathrm{f}=$ fluid

film = liquid film

in = incidence

$\mathrm{m}=$ mean

$\mathrm{p}=$ particle

$\mathrm{s}=$ solid particle

$\mathrm{t}=$ turbulent

w or wall $=$ wall surface 


\section{Abstract}

In support of an erosion evaluation for the misaligned mating surfaces of the U2 nozzle and its connector block in the $3 \mathrm{H}$ evaporator lift-separator jumper, the Engineering Modeling and Simulation Group (EMSG) has developed computational models to identify potential sites of high erosion. Two mechanisms were considered to evaluate high erosion locations representative of the actual flow process in the misaligned U2 nozzle, abrasive erosion which occurs by high wall shear of viscous liquid film, and chipoff erosion which is mainly governed by particle impingement. The results show that primary locations of the highest erosion due to particle impingement are at the occurrence of sudden change of flow direction, sudden contraction, and flow obstruction as expected. Potential damage sites due to the abrasive wall erosion are at the upstream and downstream regions of sudden changes of flow direction. 


\section{Summary}

In support of an erosion evaluation for the misaligned mating surfaces of the U2 nozzle and its connector block in the $3 \mathrm{H}$ evaporator lift-separator jumper, the Engineering Modeling and Simulation Group (EMSG) has developed computational models to identify potential sites of high erosion. This information can also be used as technical input to design an experiment to demonstrate that erosion is the primary cause of the nozzle and connector block damage.

Computational fluid dynamics (CFD) methods were applied to prototypic geometry and nominal operating conditions of the evaporator jumper to ensure that the simulations would capture the erosion phenomena expected in the facility. Two mechanisms were considered to evaluate high erosion locations introduced by the U2 nozzle misalignment. One is caused by abrasive erosion which results from high wall shear of the viscous liquid film. The other is from chip-off erosion, which is mainly governed by particle impingement. The literature information shows that a ductile wall material such as Hastalloy G3 or stainless steel is damaged by both erosion mechanisms.

For typical operating conditions of the $3 \mathrm{H}$ evaporator, the Reynolds number of the discharge flow is about $10^{5}$, corresponding to a fully turbulent flow regime. A twoequation turbulence model was used to calculate the dispersion effect of particles due to turbulent eddies. In the analysis, flow patterns, wall shear, turbulence intensity, and vorticity distributions were considered as the key parameters for capturing flow characteristics and providing information on potential failure sites caused by erosion damage.

The results show that the primary locations of erosion due to particle impingement are at the sudden changes of flow direction, sudden contractions, and flow obstructions, as expected. Potential damage sites due to abrasive wall erosion are at the upstream and downstream regions of sudden changes of flow direction.

Three sets of representative experiments were chosen to test and validate the CFD models presented in this work. All these tests were performed using sand-water slurry. The benchmarking results against the literature data for hydraulic transport and erosion tests are reasonably good, taking into account the complex nature of fluid-solid twophase phenomena. Comparisons with pressure drop data are within $15 \%$ of measurements.

All the computational results presented in this report were evaluated qualitatively to identify high erosion sites in terms of flow patterns and erosion characteristics. Detailed quantitative results for the erosion rate can be provided after the final model is benchmarked against test results and observations obtained during periodic maintenance and inspections. 


\section{Introduction}

A video inspection of the $3 \mathrm{H}$ evaporator cell interior done on March 6, 2002 revealed that a leak had developed on the evaporator pot nozzle where the lift-separator jumper connects because of misaligned fitting [1]. Additional history concerning the leaking problem of this jumper has been documented in the occurrence report (SR-WSRCHTANKW-2002-0003). High Level Waste Engineering (HLWE) has continued to investigate the jumper leakage in an attempt to identify the root cause so that corrective actions can be taken. Figure 1 is a schematic of the $3 \mathrm{H}$ evaporator lift-separator jumper including the misaligned mating surfaces and geometrical shapes of U2 nozzle and its connector block [5].

The primary cause of the jumper leakage was identified as material degradation due to wear [2]. This wear was observed at the misalignment of the U2 nozzle and connector block. A recent inspection (04/19/2002) conducted by HLWE identified thermal expansion as the primary cause of the nozzle misalignment [1]. When upward steam flow drives the viscous waste fluid into the separator jumper, this nozzle misalignment introduces a partial blockage of the mixed steam and waste flow at the nozzle upstream side, as well as a horizontal surface covered with a thin liquid waste film on the downstream side. This generates secondary flow circulation and results in waste fluid staying in contact with the downstream horizontal surface formed by the radial offset due to the misalignment of U2 nozzle and its connector block. When a solid particle or liquid droplet comes in contact with the wall surface, it can remove wall material. This phenomenon is called erosion. It is caused by mechanical and/or chemical interactions of the ambient fluid and solids against the wall surface.

In previous work [3, 4] a literature survey was performed to identify the principal mechanisms of wear for a solids laden fluid and to find out what other wear studies and experiments have been done. Available evidence suggests that the key to understanding erosion and corrosion in flow systems is a detailed knowledge of the coupled and complex phenomena of solids circulation and fluid motion. Surface wear of material by particle slurry impact is a major problem in nature, as well as in many multiphase flow industrial devices. In this work, we are mainly concerned with the latter, especially in the context of a particle-fluid slurry.

A key concern with radioactive operation of a piping system is the integrity of the pipe, fittings, and accompanying equipment. A breach could release contamination, which at a minimum would increase operational costs due to clean up and down time, but more importantly, would increase the potential radiation exposure to personnel. It is very important to thoroughly understand the effects of a slurry flow on the piping system so that proper maintenance can minimize equipment failure and guarantee safe operation. One problem arising from slurry flow is the wear it creates on the pipe wall. That wear occurs from the abrasive solids in the slurry and the wall shear of viscous liquid, which causes erosion. The chemicals in the slurry may result in corrosion and a synergistic effect of both erosion and corrosion. In this work, the erosion mechanism without any chemical reactions or temperature effects of the high speed steam and waste slurry is considered the primary cause of wear in order to simplify the problem. This simplification is justified by a material study [2] done on the damaged jumper surface which concluded that corrosion was unlikely. 
Date: $\quad 10 / 21 / 02$

The volume concentration of particles in the continuous fluid phase is one of key parameters associated with flow pattern and slurry characteristics. In this case, there is no information on solid size or contents in the waste slurry inside the evaporator jumper. The present analysis assumes that the slurry waste in the jumper has a very small solids content.

Figure 1 is a schematic of the overall $3 \mathrm{H}$ evaporator lift-separator jumper system with key major parts. The evaporator lift-separator jumper has approximately $21 \mathrm{ft}$ of pipe. The pipe and nozzle connector block diameters are 3-in schedule 40.

The primary objective of the present work is to identify potential locations of high erosion for the misaligned U2 nozzle and its connector block as illustrated in Fig. 1. 


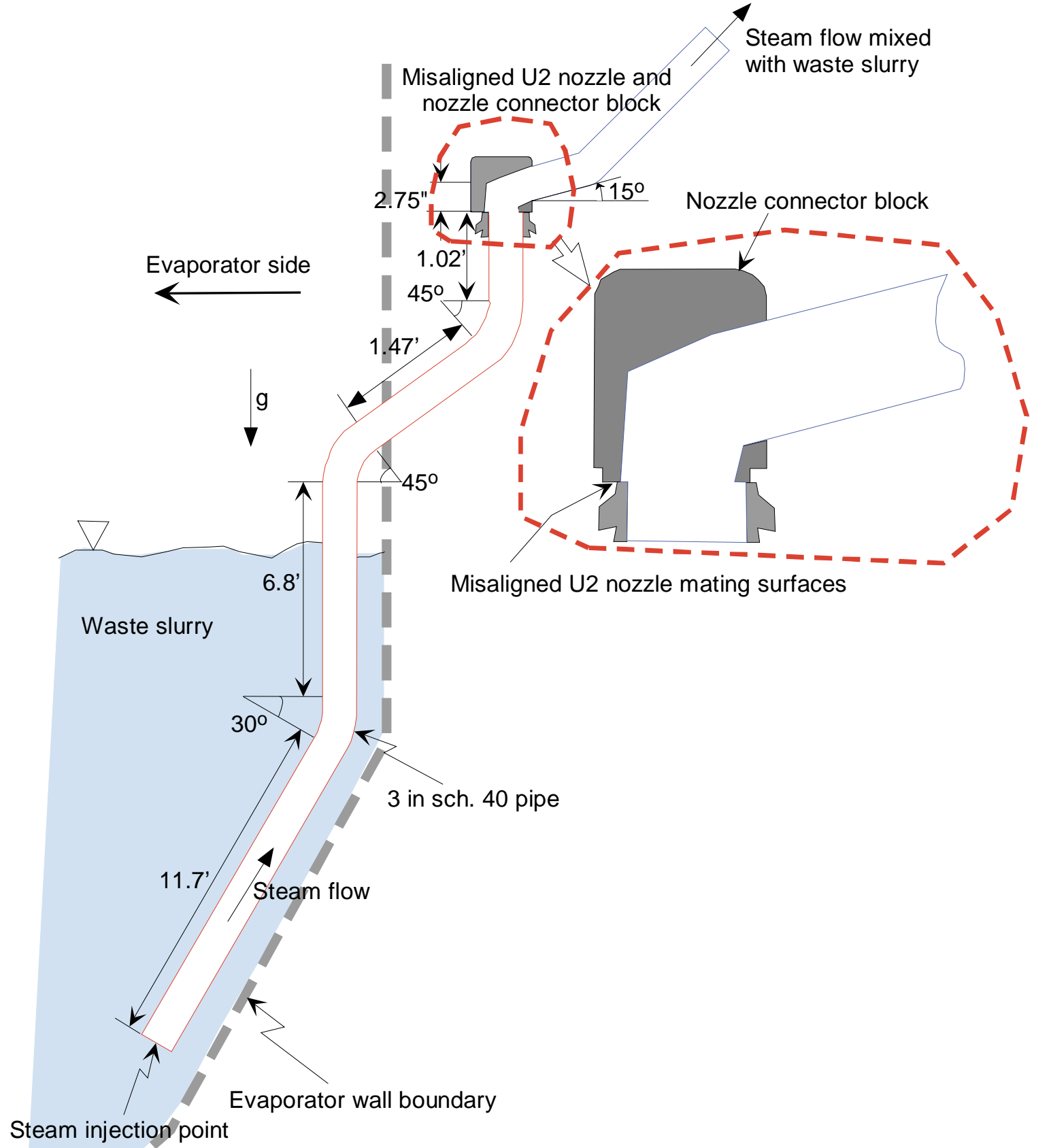

Steam injection point

Total pipe length from steam injection point to U2 nozzle: about 21'

Figure 1. Schematic of the $3 \mathrm{H}$ lift separator jumper system representing the misaligned U2 nozzle and its connector block for the present analysis. 
Report: WSRC-TR-2002-00352

Date: $\quad 10 / 21 / 02$

Page: 6 of 56
WESTINGHOUSE SAVANNAH RIVER COMPANY

EROSION ANALYSIS FOR THE MISALIGNED U2 NOZZLE AND ITS CONNECTOR BLOCK

Table 1. Design and operating conditions of the $3 \mathrm{H}$ evaporator steam injection system used in the present analysis

\begin{tabular}{|c|c|}
\hline Design and operating parameters & Dimensions and conditions \\
\hline Fluids & Waste / Steam \\
\hline Flowrates & $\begin{array}{c}\text { Steam flow (main driver): } 350 \mathrm{lbm} / \mathrm{hr} \\
\text { Waste flow (entrained by steam flow): } 25 \mathrm{gpm}\end{array}$ \\
\hline Pipe and U2 nozzle materials & Hastalloy G3 (Ni-based ductile material) [1] \\
\hline Pipe diameter & 3 in sch. $40(3.068$ in) \\
\hline System temperature & $356^{\circ} \mathrm{F}\left(180{ }^{\circ} \mathrm{C}\right)$ \\
\hline Waste fluid viscosity & $12 \mathrm{cp}$ \\
\hline Specific gravity for waste & $1.7\left(1696.6 \mathrm{~kg} / \mathrm{m}^{3}\right)$ \\
\hline
\end{tabular}

Table 2. Reference modeling conditions used for the present calculations

\begin{tabular}{|c|c|}
\hline Parameters & Operating Conditions \\
\hline Pipe diameter & 3 in sch. 40 (3.068 in) \\
\hline $\begin{array}{l}\text { Radial offset size created by misalignment } \\
\text { of the U2 nozzle mating surfaces }\end{array}$ & $3 / 16$ and $3 / 8^{*}$ inches \\
\hline Fluid velocity at inlet & $\begin{array}{l}23.15 \mathrm{ft} / \mathrm{sec} \text { corresponding to } 350 \mathrm{lbm} / \mathrm{hr} \\
\text { (steam flow) }\end{array}$ \\
\hline Particle material & $\begin{array}{l}\text { Waste droplet entrained by upward steam } \\
\text { injection }\end{array}$ \\
\hline Flow regime for waste fluid-steam & Drop flow \\
\hline Droplet size & $4.351 \times 10^{-4} \mathrm{~m}^{\star *}$ \\
\hline System temperature & $356{ }^{\circ} \mathrm{F}\left(180{ }^{\circ} \mathrm{C}\right)$ \\
\hline Fluid viscosity & Steam: $1.5 \times 10^{-5} \mathrm{~Pa}-\mathrm{sec}$ \\
\hline Waste density & $1696.6 \mathrm{~kg} / \mathrm{m}^{3}$ corresponding to $1.7 \mathrm{SG}$. \\
\hline
\end{tabular}

Note: * Reference condition

** Computed by the literature correlation 


\section{Analysis Approach and Methodology}

The present analysis focuses on that portion of the discharge piping that directly impacts flow behavior in the vicinity of the U2 nozzle. Figure 2 shows the modeling and computational domain used for the present analysis relative to the actual discharge pipe in the $3 \mathrm{H}$ evaporator. The computational domain was deliberately kept small to minimize the size of the numerical model and the associated computational time. Nonetheless, enough upstream piping was included to ensure the flow pattern reaching the nozzle would be close to that actually occurring in the plant.

From the literature [6], average flow velocity, particle size and density, and waste flow regime are key parameters in determining the transport patterns of particles in a slurry waste, which in turn, are closely related to the erosion phenomena. If steam is blown upward through the center of a vertical tube in which there is a falling liquid film, a shear stress which retards the film is set up at the interface of the liquid and gas phases. As long as the film remains fairly smooth and stable, this shear stress is usually small. The film thickness, and consequently the volume fraction of gas flow, is virtually unchanged from the value obtained with no gas flow. However, for a given liquid rate, there is a gas flow at which very large waves appear on the interface. The whole flow becomes chaotic, the gas pressure drop increases suddenly, and liquid flow begins to change from downward to upward, so that liquid can be driven by upward gas flow. This condition is known as flooding. In order to develop the critical conditions at which liquid is entrained, a minimum gas velocity is required to overcome the interfacial stress. Correlations for flooding in a vertical pipe, as shown in Fig. 1, were obtained experimentally [6]. The empirical equation available in the literature is correlated in terms of non-dimensional liquid and gas velocities. That is,

$\left(j_{g}^{*}\right)^{0.5}+m\left(j_{f}^{*}\right)^{0.5}=C$

In Eq. (1), the non-dimensional parameters $j_{g}{ }^{*}$ and $j_{f}^{*}$ are defined as

$$
j_{i}^{*}=j_{i} \sqrt{\frac{\rho_{i}}{g d\left(\rho_{f}-\rho_{g}\right)}}
$$

In Eq. (2), the subscript $i$ is $f$ for the liquid phase or $g$ for the gas phase. In the equation, $\mathrm{j}_{\mathrm{g}}$ and $\mathrm{j}_{\mathrm{f}}$ are superficial velocities for gas and liquid phases, respectively. For turbulent flow, $m$ is equal to unity. The value of $C$ is found to depend on the design of the ends of the pipes and the way in which the liquid and gas are introduced into the pipe. For tubes with sharp-edged flanges, $\mathrm{C}$ is found to be 0.725 . 


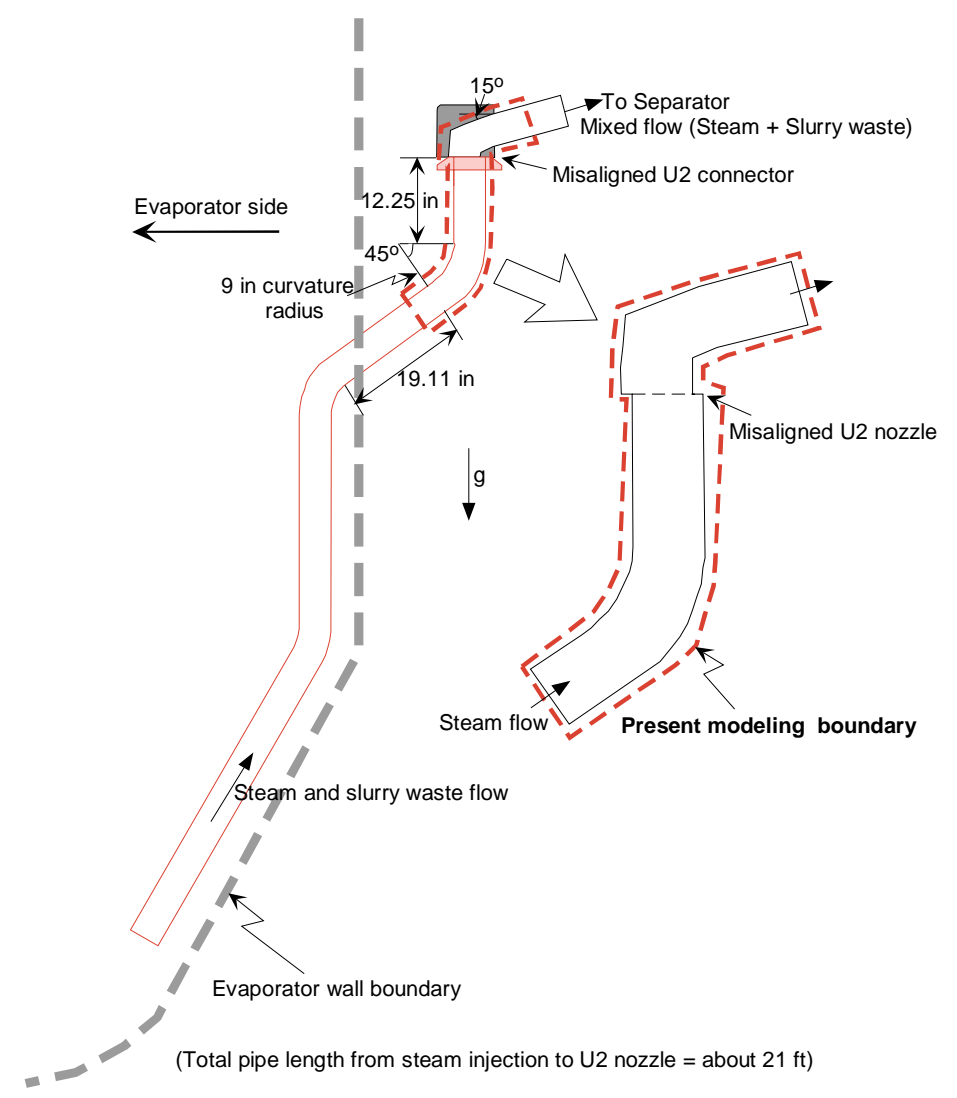

(Selection of modeling boundary representing the $3 \mathrm{H}$ evaporator jumper with misaligned U2 nozzle and its connector block)

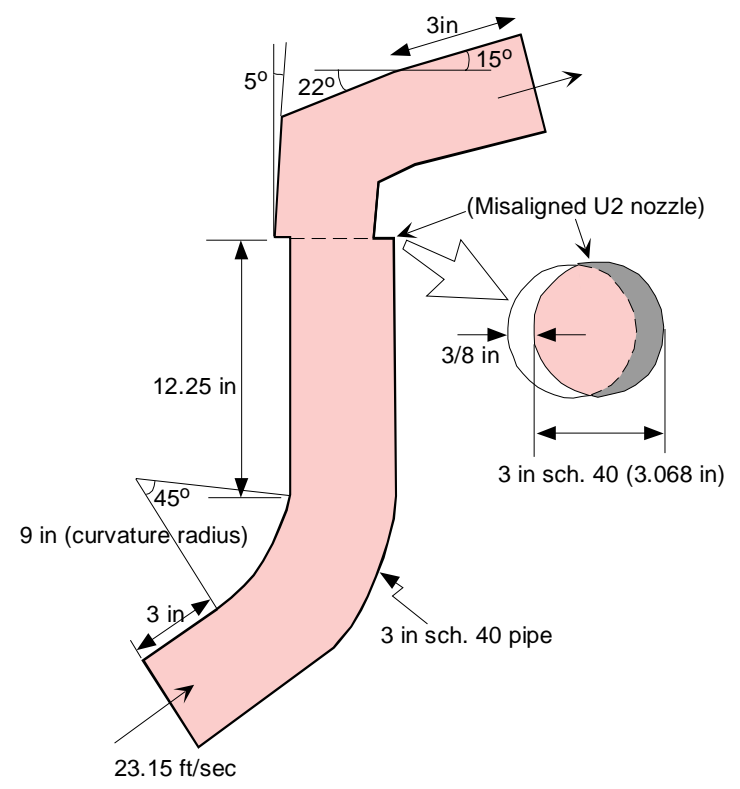

(Computational domain for the present erosion analysis)

Figure 2. Selection of modeling boundary and geometrical dimensions of computational domain as modeled for the present analysis. 
For the present conditions of the jumper system provided in Table 1 and 2, the nondimensional velocities for gas and liquid phases can be calculated as:

$$
j_{g}^{*}=0.224, \text { and } j_{f}^{*}=0.379
$$

From the flooding correlation provided in Eq. (1), the minimum gas velocity $\left(V_{c}\right)$ required to drive the liquid flow upward in the $3 \mathrm{H}$ evaporator jumper was found to be about 1.25 $\mathrm{ft} / \mathrm{sec}$. Figure 3 illustrates liquid entrainment mechanism associated with the minimum gas velocity. As shown in Table 2, the steam injection velocity at the inlet of the evaporator jumper, about $23 \mathrm{ft} / \mathrm{sec}$, is much higher than the minimum steam velocity required to drive liquid upward. Thus, the flow regime in this jumper line contains waste liquid droplets entrained by the continuous steam flowrate (350 lbm/hr).

The typical operating conditions in Table 1 show that about $25 \mathrm{gpm}$ of waste liquid flow is driven by $350 \mathrm{lbm} / \mathrm{hr}$ upward steam flow. This is about 4.5 volume percent of the total flowrate in the 21 -ft long, vertically oriented discharge pipe shown in Fig. 1. Under high gas velocity conditions on the order of $20 \mathrm{ft} / \mathrm{sec}$ at very low liquid flowrates, the surface of a liquid film on the pipe wall becomes distorted with the formation of disturbance waves, as shown in Fig. 3. Droplets of liquid are torn from the film and carried suspended in the gas. Under any given conditions within this range, a dynamic equilibrium may be established between the rate of droplet formation and the rate of droplet condensation by impingement on the existing film [9]. This phenomenon of droplet interchange is of considerable importance in transient multiphase heat and mass transfer studies. However, droplet coalescence by impingement and non-equilibrium steam condensation due to heat transfer are not considered in the present analysis. The present work uses a simplified, steady-state approach. It assumes that the gas velocity is sufficiently high that the liquid film is entirely eroded and all of the liquid is carried in the form of suspended droplets in the gas flow. The only exceptions are where the local geometry causes the droplets to separate from the gas flow and accumulate, such as at the sharp-edged horizontal corner resulting from the U2 nozzle misalignment as shown in Fig. 2.

The mean drop size of liquid atomized in the ambient steam is defined as the droplet size that can be entrained by steam injection. Nukiyama and Tanasawa (1938) correlated the droplet size, $d_{p}$, empirically in terms of flow velocity, fluid properties, and the ratio of liquid $\left(Q_{f}\right)$ to gas $\left(Q_{g}\right)$ flowrates using test data available in the literature.

$$
d_{p}=\left(\frac{585}{u_{o}}\right) \sqrt{\frac{\sigma}{\rho_{f}}}+597\left(\frac{\mu_{f}^{2}}{\sigma \rho_{f}}\right)^{0.225}\left(\frac{10^{3} Q_{f}}{Q_{g}}\right)^{1.5}
$$




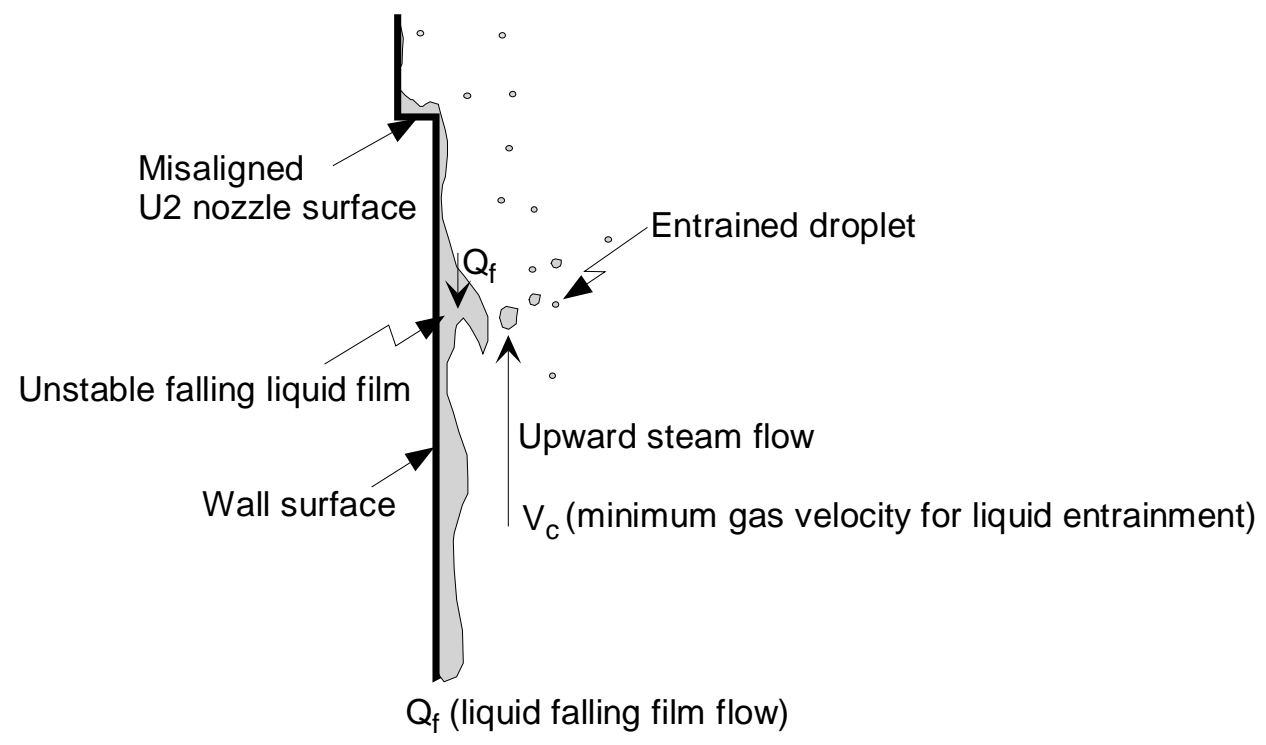

Figure 3. Liquid entrainment mechanism for the steam injection under the misaligned U2 nozzle and its connector.

In Eq. (4), $u_{o}$ is initial relative velocity of the gas and liquid phases in $\mathrm{m} / \mathrm{sec}$. Units for the other parameters are: density, $\rho_{f}$, in $\mathrm{g} / \mathrm{m}^{3}$; droplet diameter, $d_{p}$, in microns; surface tension, $\sigma$, in dyne $/ \mathrm{cm}$; and viscosity, $\mu_{f}$, in dyne.sec $/ \mathrm{cm}^{2}$, respectively.

Using the empirical correlation for the droplet size at the reference conditions provided by Tables 1 and 2, the mean droplet diameter is found to be about 435 microns.

Due to the complexities of the erosion and corrosion processes, accurate quantitative results are not expected from the CFD model without test against which to compare. At present, CFD modeling is used in a qualitative way to investigate the high erosion locations near the misaligned nozzle and its connector block by observing the existence of erosion drivers. In addition, the CFD results will help to understand the damage mechanisms associated with erosion phenomena.

\subsection{Principal Mechanisms for the Present Analysis}

From a previous literature survey [3, 4], the principal mechanisms of erosion for a slurry were identified. These are the solids or droplets content of the working fluid, regions of secondary flow recirculation and particle impingement with the component walls, and regions of high wall shear.

The current erosion analysis addresses flow patterns expected for the misaligned nozzle geometry, as well as the specific erosion mechanisms for a slurry flow, wall shear stress, particle impingement, and particle concentration. Particle concentration of the mixed fluid is about 5 volume percent as discussed earlier. The average primary flow velocity is much higher than the minimum entrainment velocity $\left(V_{c}\right)$ for $25 \mathrm{gpm}$ waste 
flow as shown in Table 3. This corresponds to the drop flow regime of gas-liquid mixture. Thus, the suspension slurry flows like a single-component flow. The flow regime is fully turbulent since Reynolds number is in the range of $10^{5}$ in terms of average flow velocity and properties.

Table 3. Entrainment velocity to initiate particle movement and average flow velocity for the reference conditions provided by Table 2

\begin{tabular}{|l|c|c|c|}
\hline $\begin{array}{c}\text { Operating conditions for } \\
\text { 3H evaporator jumper }\end{array}$ & $\begin{array}{c}\text { Pipe } \\
\text { size }\end{array}$ & $\begin{array}{c}\text { Minimum steam } \\
\text { velocity for liquid } \\
\text { entrainment } \\
\text { (computed by Eq. } \\
(1))\end{array}$ & $\begin{array}{c}\text { Mean droplet size } \\
\text { (computed by Eq. } \\
(4))\end{array}$ \\
\hline - steam flow = $350 \mathrm{lbm} / \mathrm{hr}$ & $3.068 \mathrm{in}$ & $\begin{array}{c}1.25 \mathrm{ft} / \mathrm{sec} \\
(23 \mathrm{ft} / \mathrm{sec})^{*}\end{array}$ & $435 \mathrm{microns}$ \\
\hline - waste density =1.7 S.G. & & & \\
\hline
\end{tabular}

Note: * Steam velocity corresponding to the steam supply of $350 \mathrm{lbm} / \mathrm{hr}$

The models assume that the erosion process with a homogeneous gas-droplet mist flow regime is caused by abrasive wall friction and particle impingement as discussed previously. For a slurry flow laden with large particles such as sand, the latter process may be important in elbow components or at flow obstructions. A schematic of erosion driving mechanisms is illustrated in Fig. 4. The turbulent boundary layer is generally small, but for the purpose of graphical illustrations, the shear region adjacent to the wall is greatly exaggerated in the figure.

Figure 5 shows two main mechanisms and the overall methodology considered for the present erosion analysis. Detailed discussions of the two main mechanisms of slurry erosion are provided below for insight into the erosion characteristics and the literature results at expected operating conditions in the $3 \mathrm{H}$ evaporator jumper. In this case, the slurry waste may contain solids consisting of small salt crystals.

\section{Wall Shear Stress}

The stress on pipe walls due to the shearing action of a flowing slurry was thought to be an important feature of erosion because of the ductile wall material, i.e., Hastalloy or stainless steel. Erosion of a surface can be different for the same material if the angle at which particles approach the surface changes. Literature that deals with the angle of impact for a particle approaching an eroding surface falls into two categories: particle trajectory angles that cause either ductile wear or brittle wear. Those types of wear will not be discussed here but they refer to the way material is removed from a surface. Ductile wear is defined when a surface has the highest wear rate at an impingement angle of about $30^{\circ}$ and brittle wear is at an angle of about $90^{\circ}$. Finnie [8] states that ductile wear occurs between $20-30^{\circ}$, but he adds that it is always the predominate type of wear when particles are less than 10 microns in diameter and move at "slow" velocities. Using 304L stainless steel, Burstein and Sasaki [7] state that sand particles attacking surfaces at oblique impingement angles $\left(40-50^{\circ}\right)$ remove the passive oxide layer more effectively than at $90^{\circ}$. In fact, Foley and Levy [11] showed that $304 \mathrm{~L}$ stainless steel does indeed wear fastest with a particle angle of $30^{\circ}$. Singh et al. [24] 
Date: $\quad 10 / 21 / 02$

showed that both 304 and 316 stainless steels have the same rate of wear when impinged with an air jet containing SiC particles that were 160 microns in diameter and had angular shapes. Both metals wore the fastest when the impingement angle was $30^{\circ}$ and slowest when it was $90^{\circ}$. This information is very useful when examining wear damage or designing a test because it indicates where attention must be directed to evaluate the maximum wear locations. That is, wear measurements must not be concentrated only at a section of a flow loop where the flow direction changes. This was well demonstrated by Smith and Elmore [25], who studied the wear on a steel specimen from a perpendicularly $\left(90^{\circ}\right)$ oriented slurry jet, only to find that another steel specimen, which received only oblique-angle particle attacks, unexpectedly showed more wear. The conclusion is that for ductile eroders like stainless steel or Hastalloy, measurements should be made where particles hit a surface at lower angles. Since small angles of attack by particulates is important for stainless steel, then the shear being transmitted to a surface is thought to be an important contribution to erosion. In this case, the abrasive friction due to wall shear is the key mechanism for surface erosion in a slurry flow.

The present model assumes that the volume concentration of the discrete phase and the particle size are small that particle-particle interactions and the effects of the slurry volume fraction on the continuous phase are negligible. The mixed slurry is assumed to be homogeneous with the discontinuous droplet phase distributed uniformly.

The characteristics of the turbulent fluid-wall interaction are addressed by a standard $\kappa-\varepsilon$ model. This model basically computes the turbulent eddy viscosity, $v_{\text {t }}$, by solving two transport equations for $\kappa$ (turbulent kinetic energy) and $\varepsilon$ (rate of dissipation of turbulent energy). The literature information shows that turbulent eddies are constantly lifting the particles into the fluid stream due to the fluctuations in velocity [31]. For the simulation with the wall shear mechanism, it is assumed that the friction due to the wall shear stress is the principal driver for the erosion. 
WESTINGHOUSE SAVANNAH RIVER COMPANY

EROSION ANALYSIS FOR THE MISALIGNED U2 NOZZLE AND ITS CONNECTOR BLOCK
Report: WSRC-TR-2002-00352

Date:

Page:
$10 / 21 / 02$

13 of 56

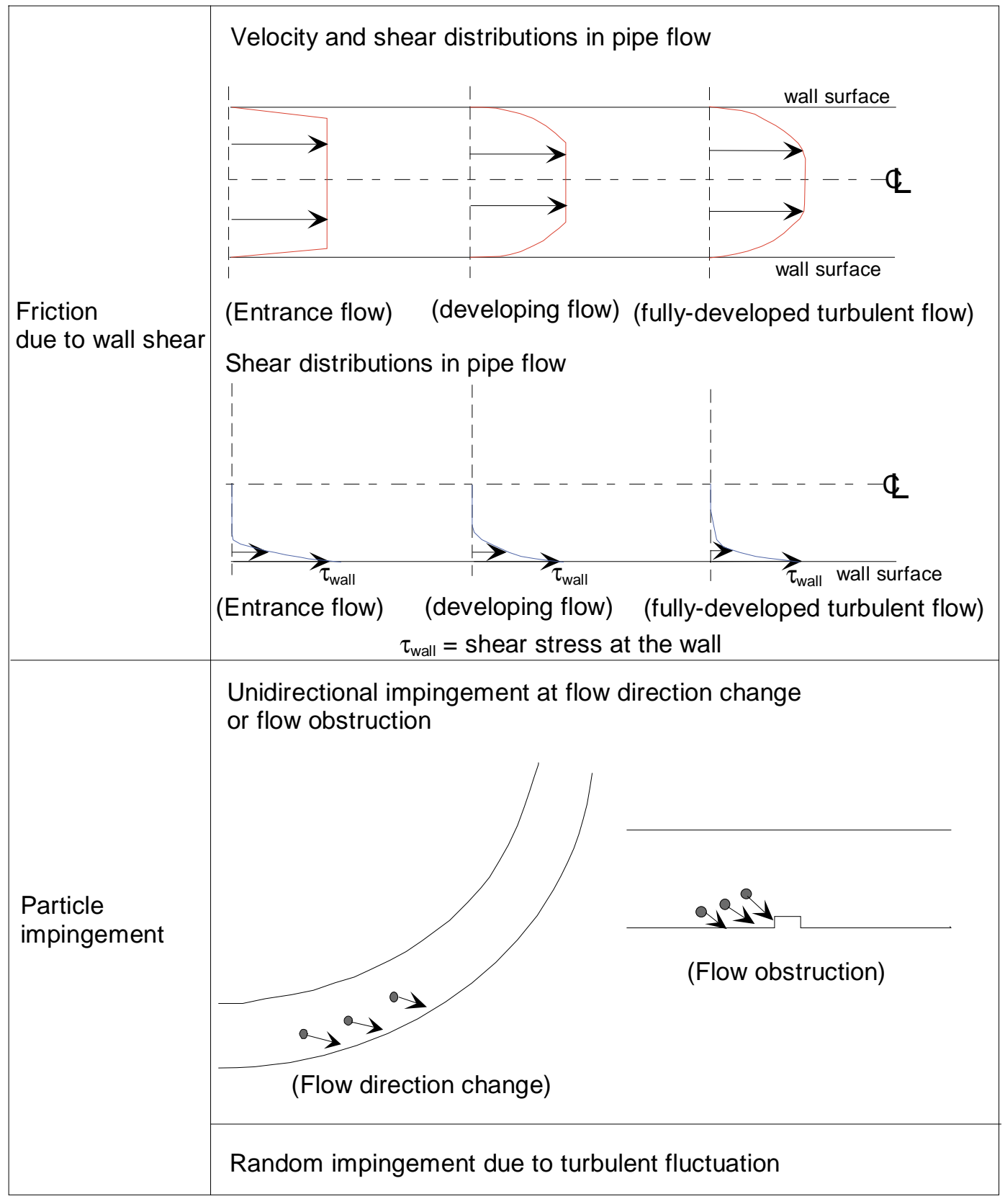

Figure 4. Main driving mechanisms of erosion in a waste slurry flow for the present analysis. 


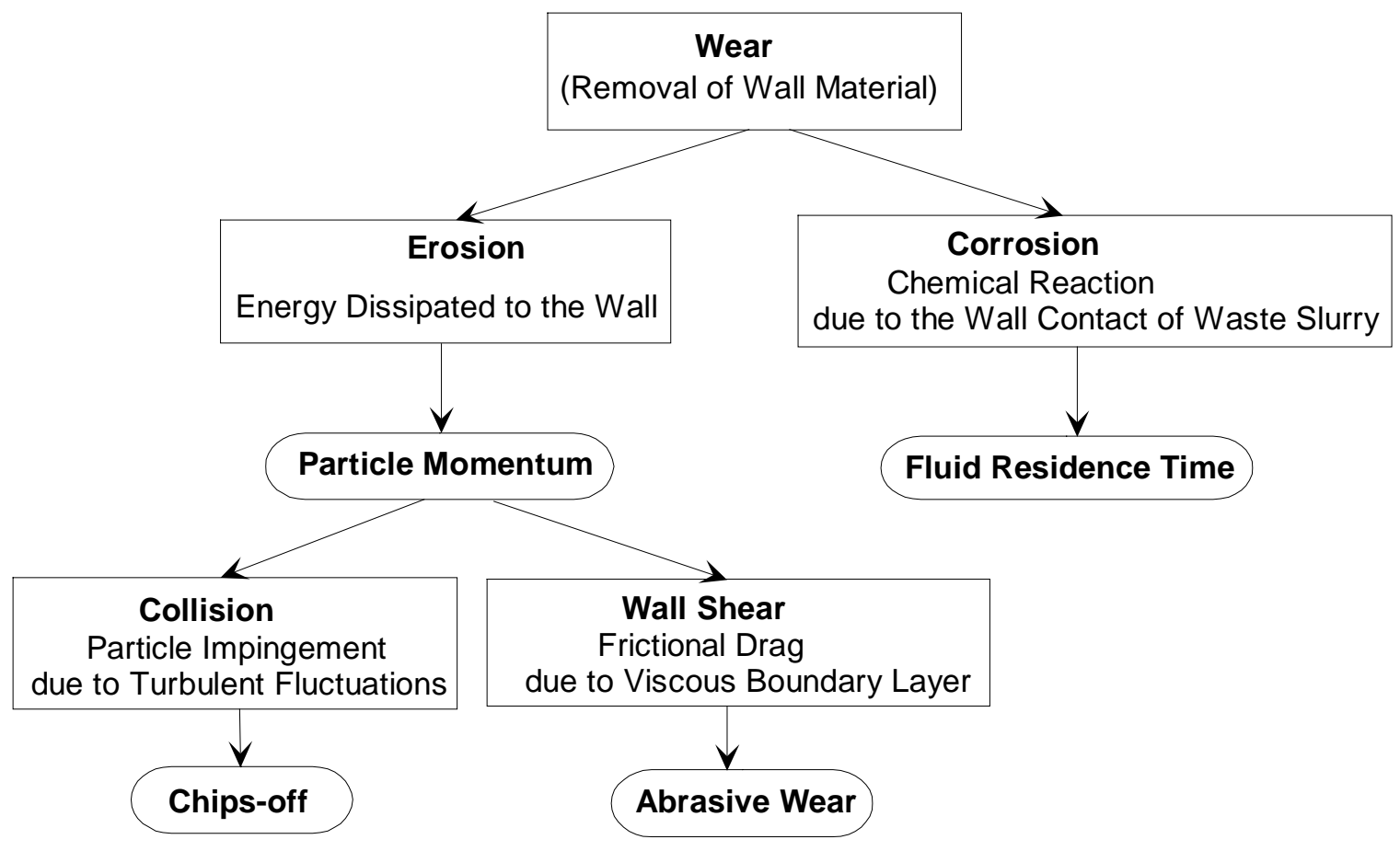

Figure 5. Main mechanisms and methodology considered for the erosion analysis of the misaligned U2 nozzle and its connector block.

\section{Particle Impingement}

While a knowledge of the wall shear stress pattern in a flow system is useful in developing insights on high stress locations, it may not be directly applicable to locations of high wear rates, especially for chip-off or brittle wear damage due to particle impingement. The difference between these two locations will increase as slurry solids become heavier and larger; that is, as the flow path of particulates become increasingly different from fluid streamlines. Erosion primarily occurs from the mechanical interaction of the particles impinging on the surfaces of the wall boundary when the flow direction changes suddenly, for instance, at pipe bends or flow obstructions with bluff bodies. Subsequently, corrosion is accelerated as impacted surfaces are exposed to the slurry chemistry. In this process the location of high wear therefore will be where erosion is the highest. To computationally estimate where high erosion locations exist, it is important to model the movement of those particulates. If the particles are very heavy and large, the particles are deposited or separated from the continuous phase, resulting in non-uniform heterogeneous flow regime and computational simulation approaches are less efficient and more expensive in estimating high wear location. However, small particles and low particle content (less than approximately 10 volume percent) in a slurry flow allow good estimates for the erosion.

Particle size has been studied by several investigators but there is not a consistent story. At one extreme, Zhong and Minemura [26] determined that erosion rate increases with size but the effect is "small" until a particle reaches 1000 microns. In the context of the present need where the target particle sizes are less than 500 microns, all 
the particles of the present erosion studies are considered small. The definition of small may allow assumptions of homogeneous flow, among others, to be valid, thus making computational tools more useful.

Note that an implicit assumption in particle size is that all the particles are uniform in size. At times this is an unavoidable simplification, but it is important to remember that in real systems the transported particles have a non-uniform size distribution. Most studies state the mean particle size without giving information on the actual distribution of particle sizes within a group. However, a group of particles having all the same size and another which has a wide range of sizes, with a mean size equal to the uniform-size group, may give different wear results. In fact, wear results from the two different groups of particles would not be expected to match because the interaction energy and the rate of material removal are nonlinear with particle size. Some experiments performed for particles with a broad quasi-logarithmic size distribution suggest that the "equivalent wear diameter" for slurry pipes or pumps is larger than the mean particle size [21, 22]. The "equivalent wear diameter" refers to a particle diameter that is assigned to a group of particles having a range of sizes, that would cause the same wear rate as a group of particles all having that same (assigned) size. While the difference between actual diameters and equivalent wear diameter should be taken into account when discussing erosion rates based on a mean particle diameter, data to support such an approach do not exist for the present analysis.

Literature information [19] showed that erosion depends mainly on the wall material, the particle velocity, and the angle of attack. In the particle-tracking model, erosion caused by particle impingement against the pipe wall is investigated. Steam flow was modeled as the continuous phase using three-dimensional mass continuity and momentum equations in an Eulerian frame of reference. Droplet particles driven by the steam flow were simulated as a dispersed second phase in a Lagrangian frame of reference to compute the their trajectories. The shape of the particles was assumed to be spherical. This simplified approach assumes that all solids are homogeneously distributed in the discontinuous droplet phase. The model assumes that the volume concentration of the discrete phase is so small that particle-particle interactions and the effects of the particle volume fraction on the continuous phase are negligible. Therefore, the response of particle is driven by the relative velocity between the particle and the fluid. This relative velocity determines the interfacial drag, which determines the motion of the particle when there are no particle-particle interactions within the flow field.

Literature data [19] showed that the erosion coefficient $\xi_{\text {erosion }}$ mainly depends on the incident particle speed, $v_{i n}$, droplet size, $d_{p}$, and the incident angle, $\beta_{i n}$. The incident angle is defined as the angle between a plane tangent to the surface at the impact location and the direction of motion of the incident particle. The form of the relationship established empirically is used for the present erosion model. That is,

$\xi_{\text {erosion }}=k v_{\text {in }}{ }^{n} f_{d}\left(d_{p}\right) f_{\beta}\left(\beta_{\text {in }}\right)$.

In Eq. (5), $k$ and $n$ are constants assumed to depend on the physical characteristics of the materials involved, and $f_{\beta}\left(\beta_{\text {in }}\right)$ describes the dependence of erosion on the particle incidence angle. In the calculations, the parameter $f_{\beta}$ is 0.96 as recommended by the literature [10] and $n$ is assumed to be zero. $f_{d}$ and $k$ are both assumed to be unity, since confirmed information on material characteristics of the current facility design is not available. Better values for the parameters in Eq. (5) would be obtained by benchmarking the CFD model to actual test data. Using the empirical constant, the 
erosion rate is estimated by summing the impingement impact of individual particles over the $n$ particles corresponding to the mass flowrate $m_{p}$.

$R_{\text {erosion }}=\sum_{i=1}^{n} \frac{m_{p, i} \xi_{\text {erosion }, i}}{A_{\text {wall }}}$

$A_{\text {wall }}$ in Eq. (6) is the area of the wall face associated with the impact angle of the particle path.

The CFD models for wall shear and particle impingement erosion with effects of flow turbulence are developed using Fluent ${ }^{\mathrm{TM}}$ [10]. Calculations are performed to estimate slurry-flow patterns, wall shear, and particle paths in the misaligned U2 nozzle jumper. The CFD methods are also applied to ensure that the present simulations could capture the erosion mechanisms expected to contribute to the damage on the misaligned mating surfaces of the U2 nozzle. A detailed description of the CFD methodology with the principal mechanisms of slurry erosion is given below.

\subsection{Computational Fluid Dynamics Methodology}

As discussed earlier, two mechanisms for erosion were identified to develop simulation methods using a CFD approach and the commercial CFD code, Fluent ${ }^{\mathrm{TM}}$ [10]. Two models were developed for the present analysis. One is the wall shear model based on abrasive wall erosion of ductile piping materials such as Hastalloy and stainless steel. Its purpose is to find the locations of high wall shear for the modeling domain shown in Fig. 2. The other model coupled steam flow with particle transport to characterize the erosive slurry flow patterns and investigate the locations of high erosion caused by particle impingement for the selected component system.

The present methodology relies on an assumption that the erosion rate estimated by the impingement model approaches that of the wall shear model when particles are homogeneously distributed in the slurry flow, the impingement angles of the particles against the wall surface are small, and particle sizes are small. The descriptions of the two models are summarized in Table 4. The wall shear model will be used to provide qualitative information on flow patterns and potential erosion damage locations, since the present work is focused on erosion of the ductile material at the misalignment of the U2 nozzle. 
Table 4. Primary purposes of the CFD models used in the present analysis.

\begin{tabular}{|c|c|c|}
\hline CFD Models & $\begin{array}{l}\text { Main Modeling } \\
\text { Assumptions }\end{array}$ & Primary Purposes \\
\hline $\begin{array}{c}\text { Wall Shear } \\
\text { Model }\end{array}$ & Homogeneous flow & $\begin{array}{l}\text { To find out the locations of high } \\
\text { abrasive erosion due to wall shear in } \\
\text { terms of key slurry flow patterns and } \\
\text { characteristics }\end{array}$ \\
\hline $\begin{array}{l}\text { Particle } \\
\text { Impingement } \\
\text { Model }\end{array}$ & $\begin{array}{l}\text { Negligible particle- } \\
\text { particle interactions, no } \\
\text { rotation, and no } \\
\text { particle fragmentation }\end{array}$ & $\begin{array}{l}\text { To investigate the locations of high } \\
\text { erosion due to particle impingement } \\
\text { and to quantify the erosion rates }\end{array}$ \\
\hline
\end{tabular}

For the calculations of the continuous slurry flow field, three-dimensional transport and continuity equations were solved in an Eulerian reference system. Detailed governing equations for the continuous phase were provided in previous work [32]. Reynolds number for the flow condition is found to be about $10^{5}$ in terms of component diameter, which corresponds to a fully turbulent regime. A two-equation turbulence model with turbulent kinetic and dissipation equations, the $\kappa-\varepsilon$ model, was used to include the effects of particle dispersion due to turbulent eddies in the continuous phase. For the wall shear model, field solutions for the Eulerian equations of the continuous slurry flow were applied to estimate wall shear stress. To simulate particle impingement trajectory, a momentum balance, including inertia, solid-fluid interfacial drag, and gravitational terms, was used in a Lagrangian reference system to calculate the trajectory of the discontinuous particles in the slurry. Thus, a Lagrangian-formulated deterministic particle equation of motion was solved via an integral method to predict particle speeds and trajectories once the continuous flow field was known. All converged solutions for the governing equations were achieved using the segregated and iterative solution technique.

As discussed above, two erosion mechanisms were considered to evaluate the high erosion locations and investigate the primary cause of wear damage in the modeling domain representing flow in the misaligned U2 nozzle. Flow patterns, wall shear, turbulent intensity, and vorticity distributions were considered key parameters for capturing flow characteristics and potential failure sites caused by erosion damage.

\subsection{Modeling Boundary Selection for the CFD Model}

The first step taken to design a scaled erosion test for a cross-flow filtration system was to identify those parts of the flow loop which may have higher levels of wear than a straight pipe [3]. Similarly, the elemental parts of the $3 \mathrm{H}$ lift jumper system were examined to identify those that might be subject to increased wear because of the U2 nozzle misalignment. These included a near- $90^{\circ}$ elbow with sharp-edge corner, a straight pipe with bluff body, a vertical pipe with the horizontal edge corner created by the U2 nozzle misalignment, and $\mathrm{a} 135^{\circ}$-bended pipe. 
Date: $\quad 10 / 21 / 02$

In the present steam-slurry approach, the upstream regions including the steam injection inlet were not considered as the modeling domain. These regions were sufficiently far removed from the nozzle region that their potential impact on the flow through the nozzle was small. The modeling domain boundary was selected so that flow direction changes at the upstream region far from the U2 nozzle would not affect the flow patterns associated with turbulent eddy motions expected near the U2 nozzle. This effect can be especially important when adjacent parts create an environment that causes more wear. Some examples are when two pipe elbows are close to each other, or when pipe connections are close to elbows. Previous analyses [3] showed that two elbows closely joined result in greater shear than in elbows in isolation. 


\section{Modeling Assumptions and Computational Domains}

Assumptions in the erosion calculations were as follows:

- The present models consider only mechanical erosion related to the loss of material from the wall surface, but they do not consider the moving boundary effects due to the material loss.

- The present analysis deals with pure erosion due to the hydrodynamic interactions of waste flow against the pipe wall so that corrosion was not considered.

- The waste flow regime is assumed to be fully turbulent, and particles are distributed homogeneously. Reynolds number is in the range of $10^{5}$ based on the design and operating conditions, and average flow velocity is much larger than the critical entrainment velocity.

- Waste fluid is assumed to have Newtonian behavior.

- Insoluble solid content in waste flow is insignificant, compared to the liquid droplets entrained by the steam flow.

- The entire domain is isothermal so that no energy balance equation is considered. Steam condensation within the modeling boundary is assumed to be negligible, since cooling across the modeling boundary is small.

- The liquid droplets are assumed to be elastic in the sense that no kinetic energy is dissipated as a result of the collision against the wall surface. This is realized through a coefficient of restitution, which is the ratio of the approach to recoil velocities and is specified as an input parameter to the code. In the present analysis, when a particle impinges a wall boundary, this ratio is assumed to be unity so that both the normal and tangential conditions result in no momentum (or energy) dissipation.

- The particle-particle interactions and the effects of the particle volume fraction on the continuous fluid phase are negligible. This depends on an assumption that the discrete solid phase is sufficiently dilute (particle concentrations of less than 5 volume percent in the present analysis).

- The particle shape contained in a waste flow is assumed to be spherical. The particle size is uniform and about 435 microns in diameter on the average as calculated by Eq. (4).

- The particles have no direct impact on the generation or dissipation of turbulence in the continuous phase.

Three-dimensional computational meshes for the modeling domain shown in Fig. 2 are presented in Fig. 6. Finer non-uniform meshes were used in the corner zones and joint sections at which potential flow direction changes and flow splits might occur. From the nodalization study, an optimum number of about 100,000 nodes was established for the final analysis of the three-dimensional erosion model. As shown in the figures, very fine meshes, less than 0.05 in long, were used near the misalignment and connection joints to capture the high velocity gradient. Flow boundary conditions at the inlet of the 
Date: $\quad 10 / 21 / 02$

computational flow domain used uniform homogeneous flow since the pipe length prior to the inlet of the present modeling domain was long enough to reach steady state flow.

Based on the modeling assumptions, the continuous and discrete phase equations are coupled to compute the particle trajectories and find the locations of high wall friction and erosion. The three-dimensional computational model was developed and solved with Fluent ${ }^{\mathrm{TM}}[10]$. All converged solutions were achieved using the segregated and iterative solution technique.

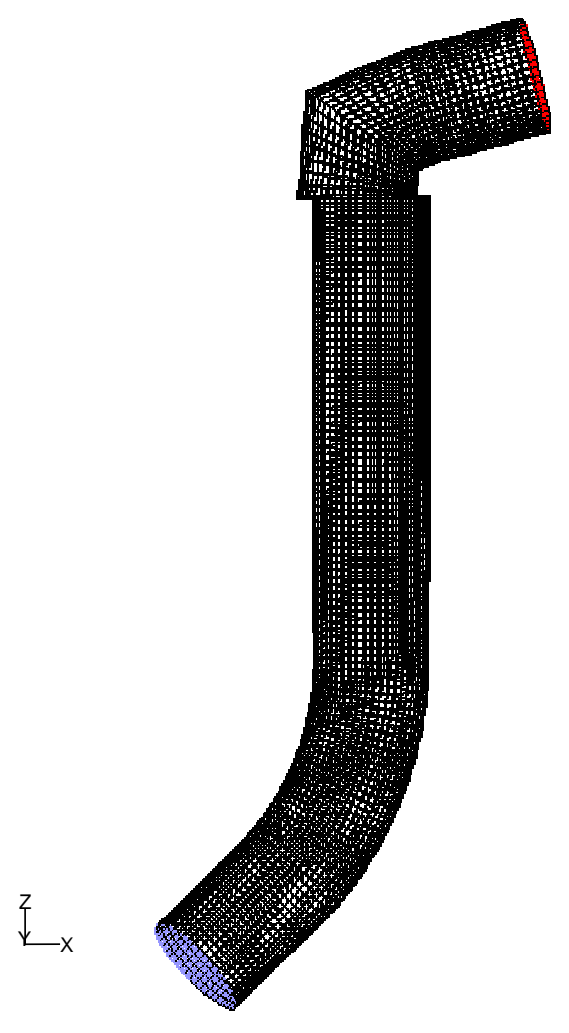

Figure 6. Computational domain and meshes of the three-dimensional model for the $3 \mathrm{H}$ evaporator lift jumper component with the misaligned U2 nozzle for the present analysis. 


\section{Results and Discussions}

The CFD models were benchmarked against test data available in the literature to examine the qualitative characteristics of slurry flow patterns and locations of high erosion. A series of the CFD analysis calculations was then performed to characterize slurry-flow patterns, wall shear, and particle paths in key components representative of the $3 \mathrm{H}$ evaporator lift-separator jumper system. Pipe diameters, lengths, the angles and shape of pipe fittings, and slurry velocities have been studied to ensure that the erosion mechanisms expected in the $3 \mathrm{H}$ system are appropriately represented in the test facility. Detailed results are discussed here. Following the discussion of benchmarking results is a discussion of the $3 \mathrm{H}$ erosion model results.

\subsection{Benchmarking Results of the Present Model}

The model predictions were benchmarked against literature data for hydraulic transport and erosion tests. Three sets of representative experiments were chosen to test the CFD models presented in this report. They are the hydraulic tests for sharp-edged (socalled miter joint) and round elbows [17] and the erosion test data for the straight pipe [15]. The test sections are shown in Fig. 7. All these tests were performed using sandwater slurry. For the hydraulic experiments through the elbows, a $30.2-\mathrm{mm}$ pipe diameter and about 990 micron particles were used. Solid concentrations for the sharpedged and round elbows were 8 and 20 weight percent, respectively. Detailed test conditions and slurry flow properties are provided in Table 5 . The results of the model predictions are compared with the test data as shown in Fig. 8. The present predictions for pressure drop as a function of flow velocity agree with the test data to within about $15 \%$.

The erosion process in a pipe cross-section is caused by random impact, abrasive wall friction, or directional impingement as illustrated in Fig. 4. The latter process becomes important when solid particles are transported non-uniformly in a slurry flow due to a flow-direction change at an elbow or flow obstruction at a bluff body, or the deposits of large particles on the bottom surface. This phenomenon was illustrated by the concentration and velocity profiles in previous work [3]. The erosion tests for the straight and horizontal pipes [15] have an inside diameter of $75 \mathrm{~mm}$. A nearly-uniform size distribution of sand of an approximate diameter of $0.67 \mathrm{~mm}$ with a true specific gravity of 2.7 was used. 


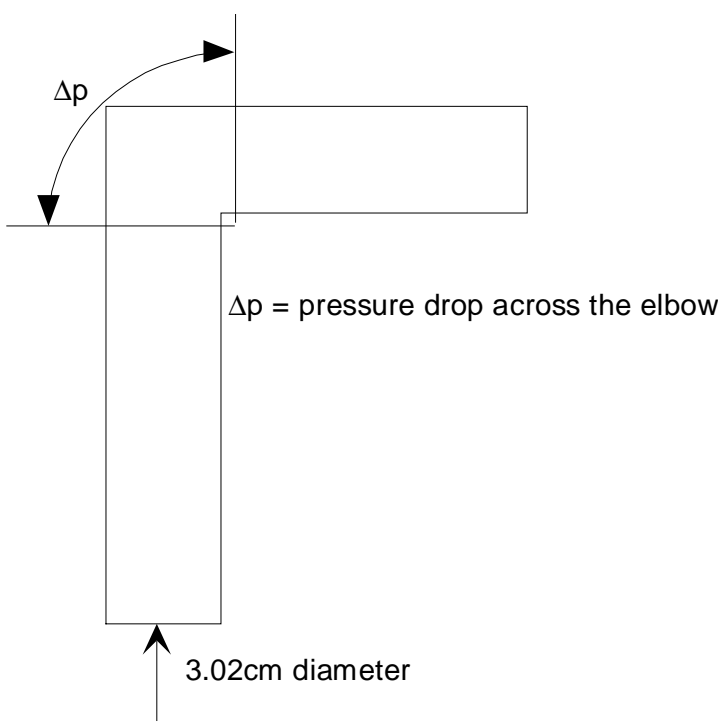

( $\mathrm{R}=0$ : Sharp-edged elbow)

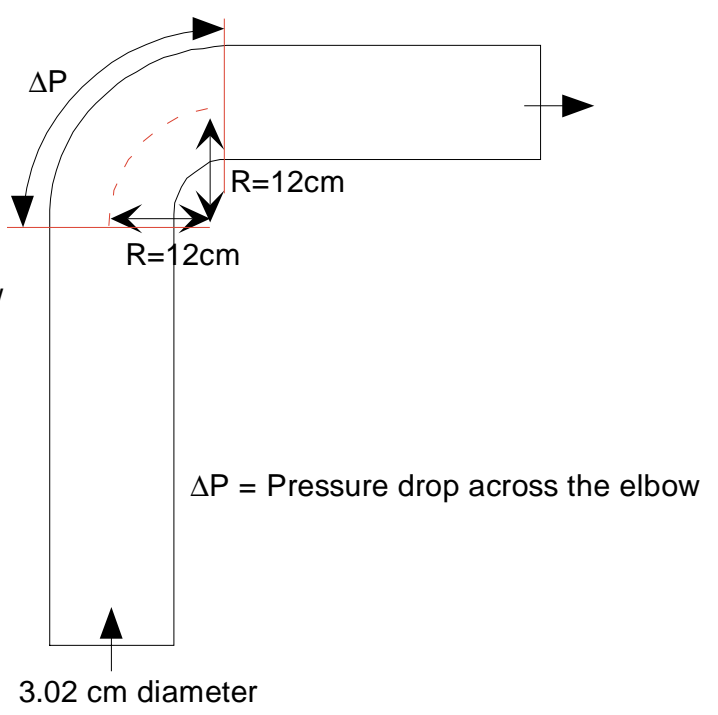

( $R=12 \mathrm{~cm}:$ Round elbow)

Figure 7. Test sections of the two elbows used in the slurry experiments [17].

The solid volume concentration in the slurry mixture was 11 volume percent. The slurry velocity was $2.83 \mathrm{~m} / \mathrm{sec}$. Detailed test conditions used in the experiment are summarized in Table 6 . The erosion was measured at 8 points along the pipe circumference with an ultrasonic thickness meter. The particle impingement model was run using the test conditions for the straight pipe.

Figure 9 shows quantitative distributions of erosion for a $75-\mathrm{mm}$ straight pipe due to particle impingement. Contour plots for solid concentrations in the slurry flow at the cross sectional exit plane of the horizontal pipe are shown in Fig. 9a. Note that locations of high erosion predicted by the particle impingement mechanism are consistently near 45 degrees from the bottom surface of the horizontal pipe. Erosion from slurry flow at the bottom surface of the pipe cross-section is reduced quickly due to the solid layer formed by deposited particles. The solid deposits protect the pipe wall from erosion as they move along the horizontal direction. The particles gather toward the bottom of the pipe cross-section as they travel downstream in the continuous phase as shown in Fig. 9 a. The results of the benchmarking against the straight pipe demonstrate that erosion does not occur near the top surface of the pipe cross-section since large particles (670 microns) move downward due to gravity as they are transported by slurry flow. The prediction results are compared with the test data as shown in Fig. 10.

The results show that the predictions of the particle impingement model are in good qualitative agreement with the data taking into consideration the very complex nature of two-component turbulent flows. Detailed quantitative benchmarking of the present models with actual tests would be required to quantify the erosion rate in a full-scale facility. Such a comparison would result in a validation of the erosion calculations, and would allow the test results to be applied to a quantitative estimation of erosion rates in the actual facility. 
Table 5. Test conditions for the pressure drop measurements across the elbows

\begin{tabular}{|c|c|c|}
\hline \multicolumn{3}{|c|}{ Geometry and fluid-particle properties } \\
\hline $\begin{array}{c}\text { Geometrical } \\
\text { shape of elbow }\end{array}$ & $\begin{array}{l}\text { Sharp-edged elbow } \\
\text { (see Fig. 7) }\end{array}$ & $\begin{array}{l}\text { Round elbow } \\
\text { (see Fig. 7) }\end{array}$ \\
\hline $\begin{array}{c}\text { Curvature radius } \\
\text { of elbow }\end{array}$ & $\mathrm{R}=0 \mathrm{~cm}$ & $R=12 \mathrm{~cm}$ \\
\hline Pipe diameter & $30.2 \mathrm{~mm}$ & $30.2 \mathrm{~mm}$ \\
\hline Water only & $\begin{array}{l}\text { Fluid density }=998.2 \mathrm{~kg} / \mathrm{m}^{3} \\
\qquad \text { Viscosity }=1 \mathrm{cp}\end{array}$ & $\begin{array}{l}\text { Fluid density }=998.2 \mathrm{~kg} / \mathrm{m}^{3} \\
\qquad \text { Viscosity }=1 \mathrm{cp}\end{array}$ \\
\hline Average velocity & 0.85 to $2.92 \mathrm{~m} / \mathrm{sec}$ & 0.67 to $3.0 \mathrm{~m} / \mathrm{sec}$ \\
\hline Slurry & $\begin{array}{l}\text { Water suspended with particles } \\
\text { Fluid density }=998.2 \mathrm{~kg} / \mathrm{m}^{3} \\
\qquad \text { Viscosity }=1 \mathrm{cp} \\
\text { Particle density }=2500 \mathrm{~kg} / \mathrm{m}^{3} \\
\text { Particle diameter }=990 \mathrm{microns} \\
\text { concentration }=8 \mathrm{w} / \mathrm{o}\end{array}$ & $\begin{array}{l}\text { Water suspended with particles } \\
\text { Fluid density }=998.2 \mathrm{~kg} / \mathrm{m}^{3} \\
\qquad \text { Viscosity }=1 \mathrm{cp} \\
\text { Particle density }=1100 \mathrm{~kg} / \mathrm{m}^{3} \\
\text { Particle diameter }=970 \mathrm{microns} \\
\text { Particle concentration }=20 \mathrm{w} / \mathrm{o}\end{array}$ \\
\hline
\end{tabular}




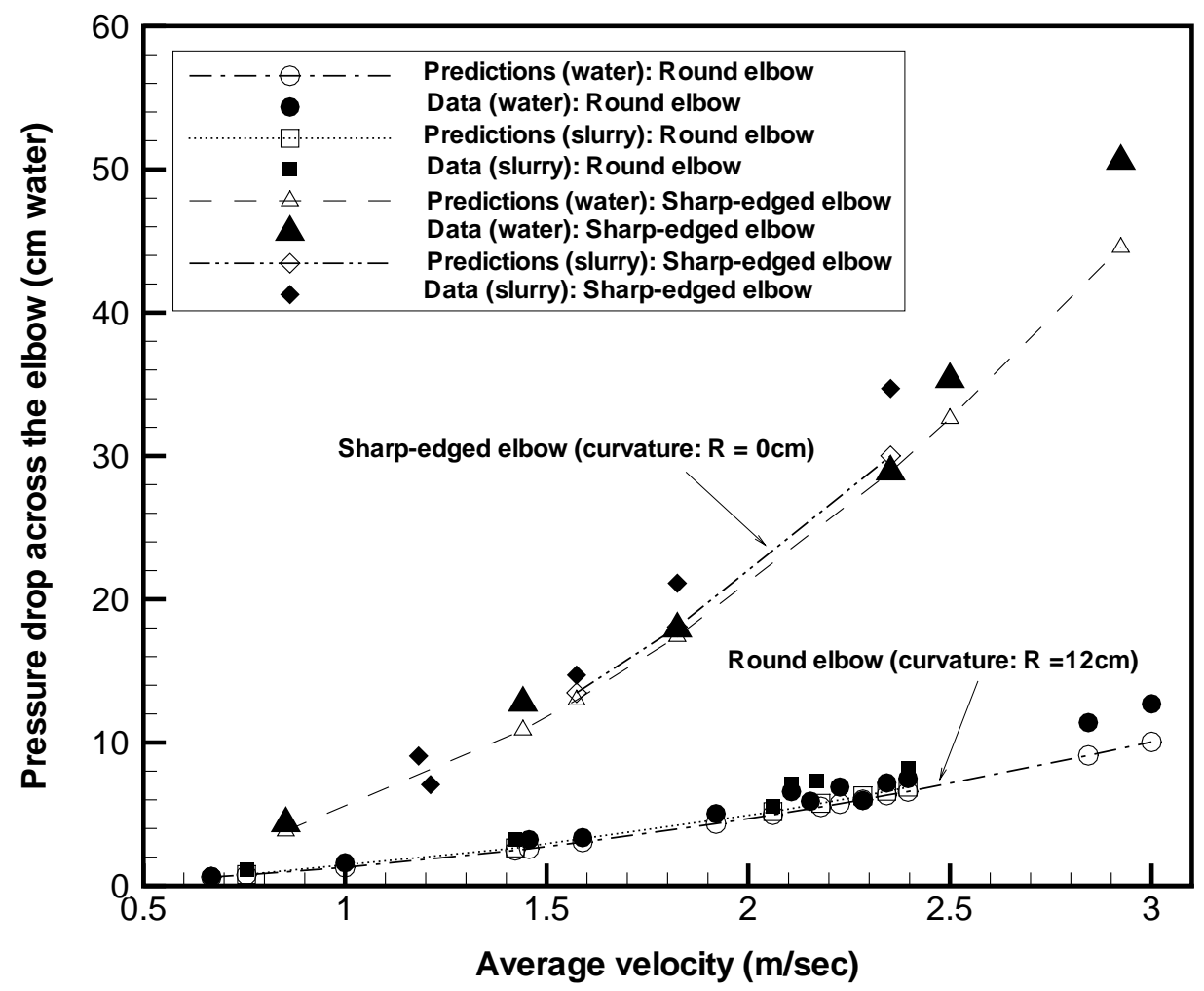

Figure 8. Comparison of predictions with the test data available in the literature [17] using the standard $\kappa-\varepsilon$ turbulent model.

Table 6. Test conditions of the literature data [15] used in the present benchmarking of the present erosion model.

\begin{tabular}{|c|c|}
\hline Design and operating parameters & Conditions \\
\hline Test section geometry and orientation & Straight and horizontal pipe \\
\hline Pipe diameter & $75 \mathrm{~mm}$ \\
\hline Slurry materials & Water and sand \\
\hline Sand particle size & $0.67 \mathrm{~mm}$ \\
\hline Particle density & 2.68 specific gravity \\
\hline Average slurry velocity & $2.83 \mathrm{~m} / \mathrm{sec}$ \\
\hline Particle concentration & 11 volume percent \\
\hline
\end{tabular}




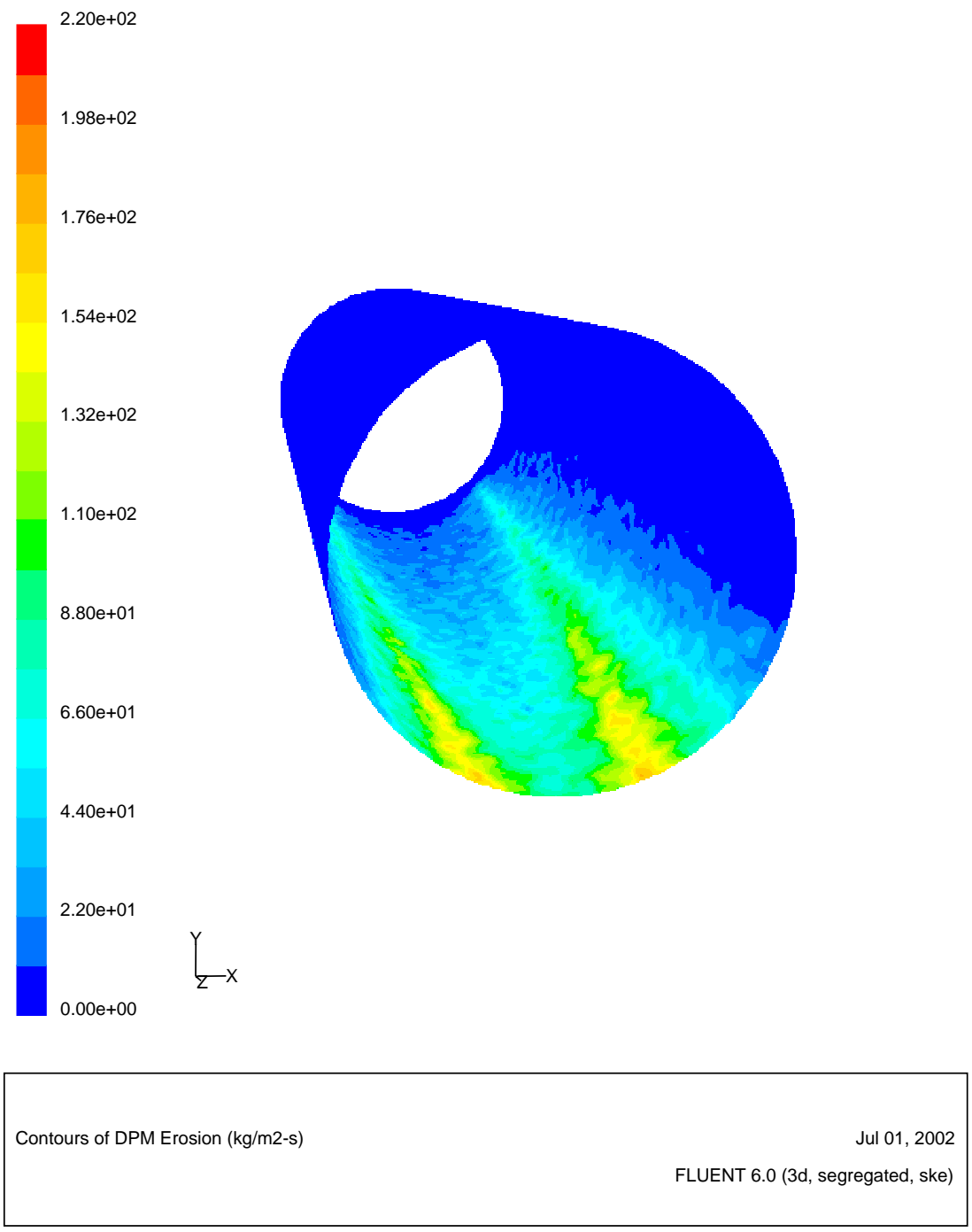

Figure 9. Erosion contour plot due to the particle impingement for horizontal pipe available in the literature [15] using standard $\kappa-\varepsilon$ turbulent model. 
Date: $\quad 10 / 21 / 02$

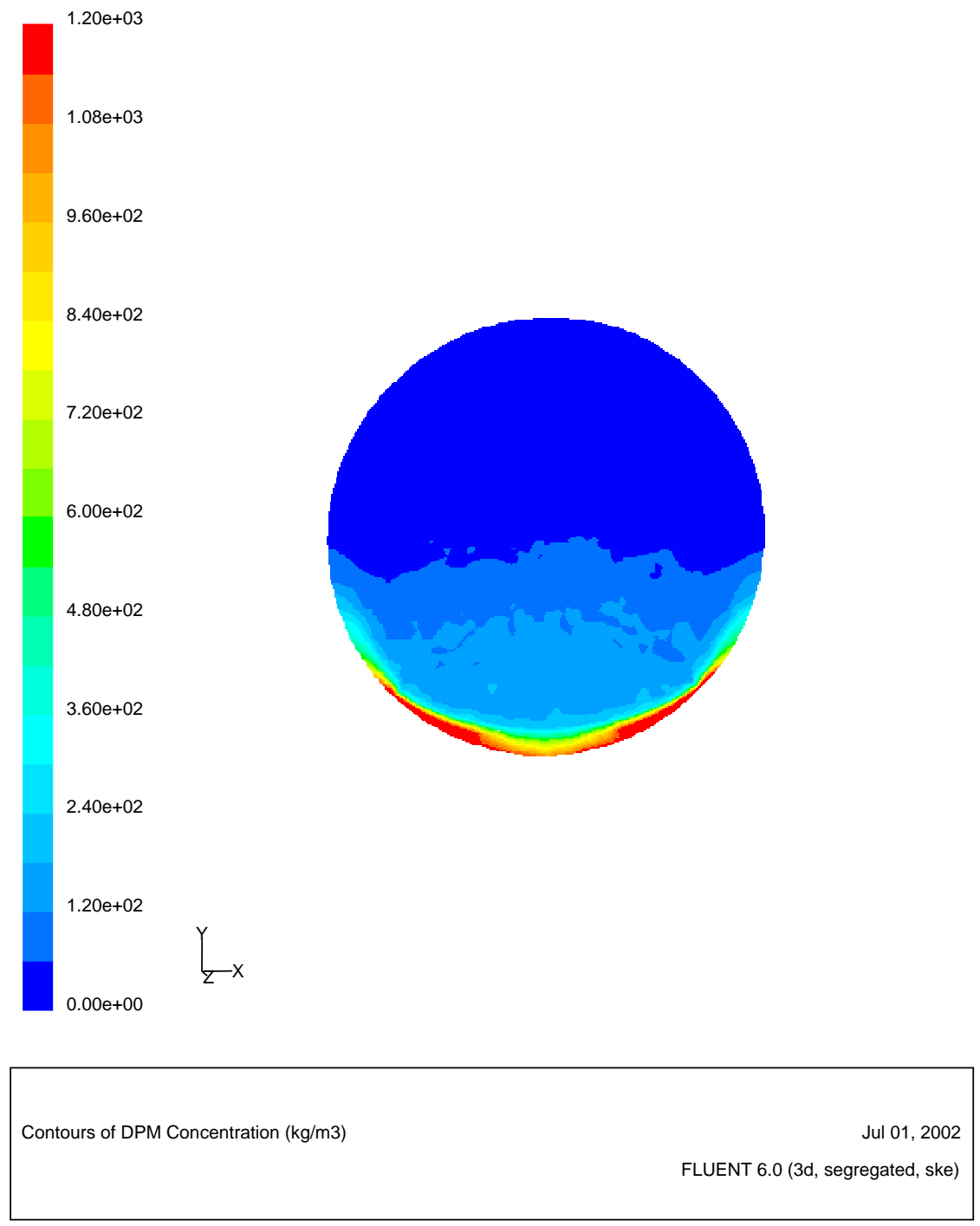

Figure 9a. Solid concentrations of slurry flow at the exit plane of the horizontal pipe available in the literature experiment [15] using a standard $\kappa-\varepsilon$ turbulent model. 

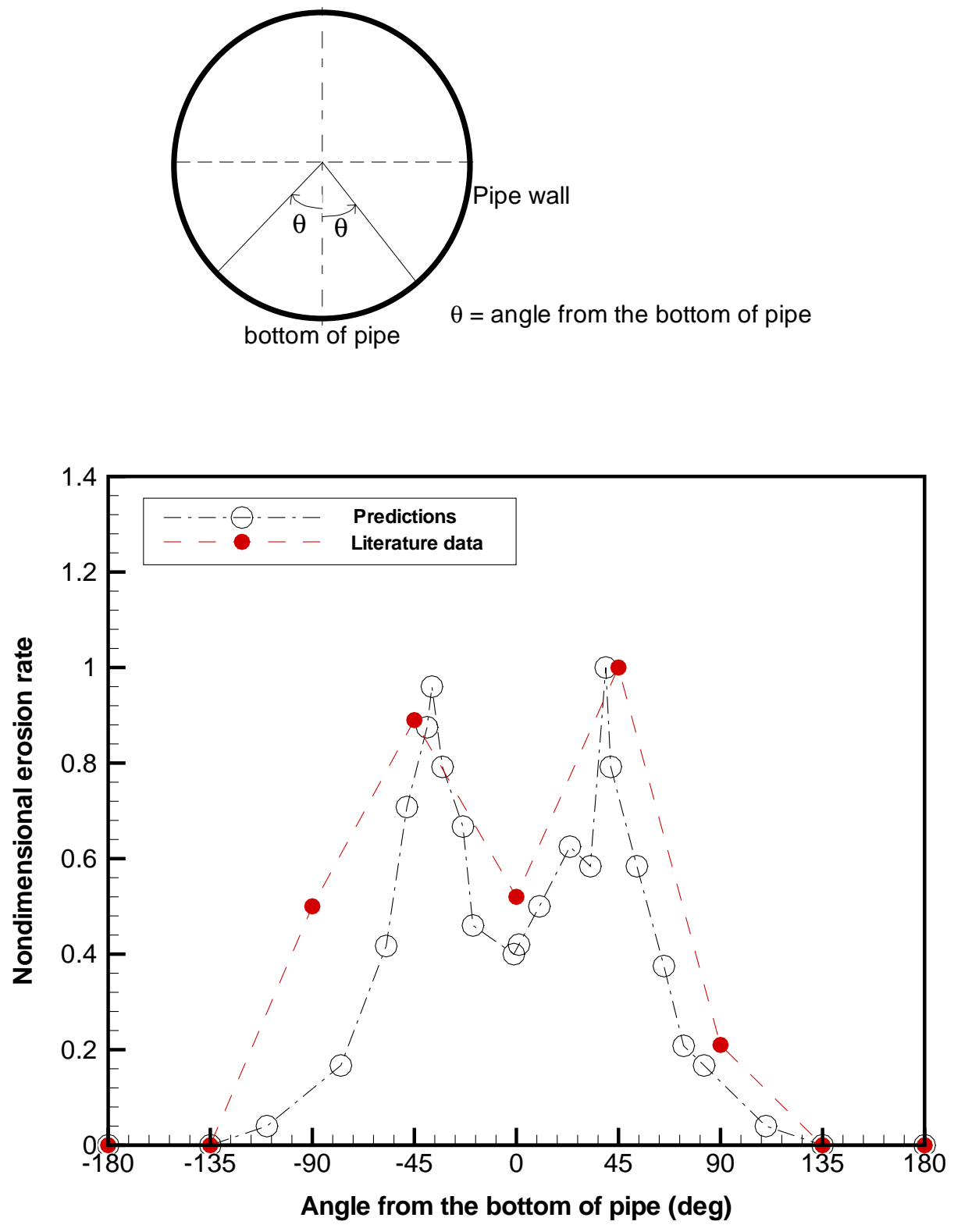

Figure 10. Comparison of predictions with the erosion test data for horizontal pipe available in the literature [15] using the standard $\kappa-\varepsilon$ turbulent model with discrete solid phase. 


\subsection{Results of the Erosion Model for the Misaligned U2 Nozzle}

The modeling calculations of the misaligned nozzle were performed for $534 \mathrm{gpm}$ steam flow $\left(180^{\circ} \mathrm{C}, 23.15 \mathrm{ft} / \mathrm{sec}\right)$ as the continuous phase, and $25 \mathrm{gpm}$ slurry flow as discontinuous phase. Detailed modeling conditions are shown in Table 1 and Table 2. From the nominal operating conditions, slurry volume concentrations in fluid system were found to be about 5 percent, assuming that slurry waste (1.7 specific gravity, $12 \mathrm{cp}$ viscosity) is carried and entrained by high speed steam flow. Since the volume fraction of the discontinuous phase determines the flow regime, this corresponds to a homogeneous gas-droplet flow regime [6]. Under these flow conditions, the mean droplet size of slurry entrained by the upward steam flow was found to be about 435 microns using a literature correlation, Eq. (4). As discussed in the solution methodology section, the present analysis assumed that heat and mass transfer effects, such as steam condensation, were negligible. About $90 \%$ of the wall surface is insulated, and the slurry volume fraction dispersed in the continuous phase is very small.

The calculation results show that maximum velocity is reached at the region of flow direction change and the largest velocity fluctuation due to flow turbulence occurs at the downstream side of the misaligned mating surfaces as shown in Fig. 11. In this case, the turbulence intensity is an indicator of flow fluctuation, which is closely related to the radial dispersion of the slurry particles. The turbulence intensity, $I$, is defined as the ratio of the root-mean-square of the velocity fluctuations to mean flow velocity. That is,

$$
I=\frac{\sqrt{\frac{1}{3}\left(u^{\prime 2}+v^{\prime 2}+w^{\prime 2}\right)_{a v g}}}{V_{a v g}} \approx 0.8165 \frac{\sqrt{\kappa}}{V_{a v g}}
$$

In Eq. (7) $u^{\prime}, v^{\prime}$, and $w^{\prime}$ are local velocity fluctuations in the $\mathrm{x}, \mathrm{y}$, and $\mathrm{z}$ directions and $V_{a v g}$ is the mean velocity magnitude. The turbulence intensity is proportional to the square root of the turbulent kinetic energy, $\kappa$, for a given mean fluid velocity. The literature information [30] shows an erosion decrease with increasing turbulence intensity, since the degree of slurry interactions with the wall boundary decreases with increasing turbulence. Figure 12 shows static pressure distributions corresponding to the flow distributions shown in Fig. 11. The pressures shown in the figure are in gauge pressure.

Secondary flow circulation is usually developed due to unbalanced shear stress at pipe bends or sharp corners such as the region downstream of the U2 nozzle misalignment as shown in Fig. 2. The intimate connection between unbalanced shear stresses, $\tau$, and vorticity, $\omega$, is made even clearer by noting that the viscous term in the momentum equation can be written as

$$
\nabla \cdot \tau=\nabla \bullet(\mu \nabla \vec{v})=-\mu \nabla \times(\nabla \times \vec{v})=-\mu \nabla \times \omega
$$

As shown in Eq. (8), an unbalanced shear stress can only exist when the vorticity is nonzero. Thus, the existence of flow rotation means that a fluid particle is subjected to net viscous forces. Figure 13 shows large flow circulation near the downstream side of the U2 nozzle misalignment. The flow circulation makes the flow slow down, resulting in increased flow residence time. The flow circulation and increased flow residence time are closely related to the wear damage of the misaligned surface due to the abrasive material and high wall shear. When the downstream region of the U2 nozzle has a smooth and round elbow as shown in Fig. 14, a smaller circulation loop is developed 
downstream of the misaligned nozzle surface, compared to the flow patterns of the sharp-edged U2 nozzle connector block. The results show that erosion impact due to the geometrical change of the elbow is insignificant.

Radial velocity distributions in the upstream and downstream regions of the nozzle misalignment are shown in Fig. 15. It is noted that maximum velocity magnitude occurs at the inner wall of the elbow and just at the beginning of the flow direction change and then quickly disperses toward the center of the pipe just after the bending region as a result of large secondary flow generation. The evidence of high turbulence and large flow vortices resulting from the generation of secondary flows is shown in Figs. 16 and 17. These phenomena are consistent with the experimental observations for a pipe bend [30]. Figure 18 shows vorticity distributions at the vertical mid-plane of the $3 \mathrm{H}$ evaporator lift-separator jumper.

Erosion damage of ductile materials such as 304 stainless steel is determined mainly by the shear stress mechanism as discussed earlier. Wall shear distributions caused by the continuous steam velocity distributions shown in Figs 11 and 13 are presented in Fig. 19. An effect not shown in Fig. 19 is liquid film formation on the downstream horizontal surface formed by the U2 nozzle misalignment. This film has an important impact on abrasive shear erosion because secondary flow and pressure gradients drive the viscous liquid film horizontally toward the continuous mainstream flow as shown in Fig. 20.

Consider a thin liquid film formed on the downstream surface of the U2 nozzle misalignment. Assuming liquid film motion driven by a secondary flow and a pressure gradient in the recirculation region as shown in Fig. 20, the wall shear stress, $\tau_{w}$, caused by the thin film can be estimated in terms of the pressure gradient and mean film velocity. Using steady-state and boundary layer approximations, and assuming convective effects in the thin viscous film on the horizontal surface to be small in comparison with viscous effects, the general Navier-Stokes equation can be reduced to

$0=-\left(\frac{d P}{d x}\right)+\mu_{\text {film }}\left(\frac{d^{2} u}{d y^{2}}\right)$

The coordinate system and notations used in Eq. (9) are shown in Fig. 20. In Eq. (9) $\mu_{\text {fimm }}$ and $\mathrm{P}$ are dynamic viscosity of the liquid film and local pressure, respectively. The velocity of the film flow can be determined by the following boundary conditions:

$u=0$ at $y=0$ (No-slip condition at the wall surface)

$u_{m}=\frac{1}{\delta} \int_{0}^{\delta} u d y$

$u_{m}$ and the pressure gradient can be obtained from the CFD results, and film thickness $\delta$ is assumed to be a known quantity. Using the above boundary conditions, Eq. (10) and (11), film flow velocity $u(y)$ can be determined by Eq. (9). That is,

$$
u=\frac{1}{2}\left(\frac{d P}{d x}\right) y^{2}+\left(\frac{2}{\delta}\right)\left(u_{m}-\frac{1}{6 \mu_{\text {film }}}\left(\frac{d P}{d x}\right) \delta^{2}\right) y
$$

Wall shear stress on the misaligned horizontal wall surface can be determined by Eq. (12). That is, 


$$
\begin{aligned}
\tau_{w} & =\mu_{\text {film }}\left(\frac{d u}{d y}\right)_{y=0} \\
& =\mu_{\text {film }}\left(\frac{2 u_{m}}{\delta}+\frac{\delta}{3 \mu_{\text {film }}}\left(-\frac{d P}{d x}\right)\right)
\end{aligned}
$$

Eq. (13) shows that wall shear stress is caused by viscous film motion and the pressure gradient, which is established by the falling liquid droplets and secondary flow patterns.

An estimate of the stable film thickness, $\delta$, is required to quantify the wall shear stress. A minimum amount of liquid is required on the horizontal surface, or shelf, created by the nozzle misalignment to make the formation of a film more energetically favorable than having the liquid remain as discrete droplets. The energy of the formation is the surface energy represented by the surface tension times the surface area. For the liquid film, this is just the shelf area, assuming that the film would remain essentially flat as it gets thicker. The surface area for a droplet configuration would be the surface area of an individual droplet of diameter $d_{p}=435$ microns, multiplied by the number of droplets needed to form the volume of liquid in the film, or the shelf area times the film thickness. The criterion for the film to be preferred over the droplet configuration is that the surface energy associated with the film be less than that of the equivalent number of droplets. With a bit of algebra, this criterion can be expressed as

$\delta>\frac{R_{\text {droplet }}}{3}$,

or 72.5 microns based on the estimated droplet diameter.

From the present CFD results, the pressure gradient $(-d P / d x)$ was about $64.10 \mathrm{~Pa} / \mathrm{m}$, and film flow rate was $1.577 \mathrm{gm} / \mathrm{sec}$ corresponding to about $0.6 \%$ of total liquid entrainment through the $\mathrm{U} 2$ nozzle connector. The total pressure differential resulting from the calculated pressure gradient over the shelf dimension, $3 / 8 \mathrm{in}$., is about 0.6 Pa. If this pressure differential is used to estimate the change in liquid film height over the 3/8-in shelf, it represents a height of 37 microns. Assuming a mean film height of 72 microns based on the stability criterion of Eq. (14), the average film velocity would be about $10.6 \mathrm{~cm} / \mathrm{sec}$. This film thickness is considerably smaller than the estimated droplet diameter of 435 microns, and would imply that the droplets collapse and spread out as they impact the pipe wall and flow downward to form the film along the horizontal shelf.

Applying these values in Eq. (13) gives a wall shear stress of $35 \mathrm{~Pa}$. This is considerably larger than the shear stresses noted in other regions of the discharge piping and supports the observation of erosion on the downstream side of the nozzle misalignment. Nonetheless, the analysis must be considered a rough estimate. The detailed results for maximum shear stresses and relative erosion rates are summarized in Table 7.

The results for particle trajectories and high erosion locations due to waste droplet impingement are shown in Fig. 21. Potential sites of high erosion are the outer elbow wall and the upstream region of the misaligned surface. This results from the high rate of particle impingement on the upstream region of the misaligned wall surface due to the partial flow blockage, as well as the outer surfaces downstream of the elbow due to the 
inertia of the particles at the $90^{\circ}$ change in flow direction. Figure 22 shows erosion contour plots due to particle impingement for the upstream and downstream regions of the nozzle misalignment. Discontinuous droplet distributions near the U2 nozzle are shown in Fig. 23. The results show that most droplets, which are much heavier than the continuous phase, are present in the slower velocity regions and the corner zone after the flow direction changes due to the high inertia of the droplets.

Figure 24 shows detailed flow patterns along the mid-plane of the evaporator jumper including secondary flow circulation near the misaligned nozzle surface. The paths of particles released from the mid-plane of the evaporator jumper are shown in Fig. 25. It is noted that flow residence time near the downstream corner zone (about 0.7 second) is much larger than the core fluid residence time (about $10^{-3}$ second), since the secondary flow circulates much slower than the main stream velocity. This makes abrasive erosion due to high wall shear on the misaligned downstream surface larger than impingement erosion on the same surface, which will eventually lead to potentially high corrosion damage from the increased exposure time of the eroded surface.

Figure 26 shows flow patterns associated with particle impingement of waste droplets. The figure shows that secondary flow is always generated after the flow direction is changed. This is closely related to abrasive erosion due to wall shear stress. Figure 27 shows potential abrasive erosion locations due to wall. It should be noted that the viscous film layer on the horizontal surface downstream of the nozzle causes high erosion damage due to wall shear when secondary flow circulates near the corner zone of the connector block.

Potential erosion sites due to the impingement of waste droplets in a steam flow are shown in Fig. 28. Primary locations of the highest erosion due to particle impingement are at sudden changes of flow direction, sudden contractions, and flow obstructions as expected. Erosion damage of ductile material such as Hastalloy or stainless steel is mainly governed by high wall shear and low angle impingement of particles as discussed earlier. As shown in Fig. 27, the present results show that potential damage sites due to abrasive wall erosion are at the upstream and downstream regions of sudden change of flow direction.

Based on the two erosion mechanisms being discussed, high wall shear and chip-off erosion, and the operating conditions shown in Tables 1 and 2, erosion evaluations for two different offset sizes and two different types of nozzle connector blocks were performed. All the results were estimated qualitatively in terms of the relative scale of erosion rate with respect to a reference value. 

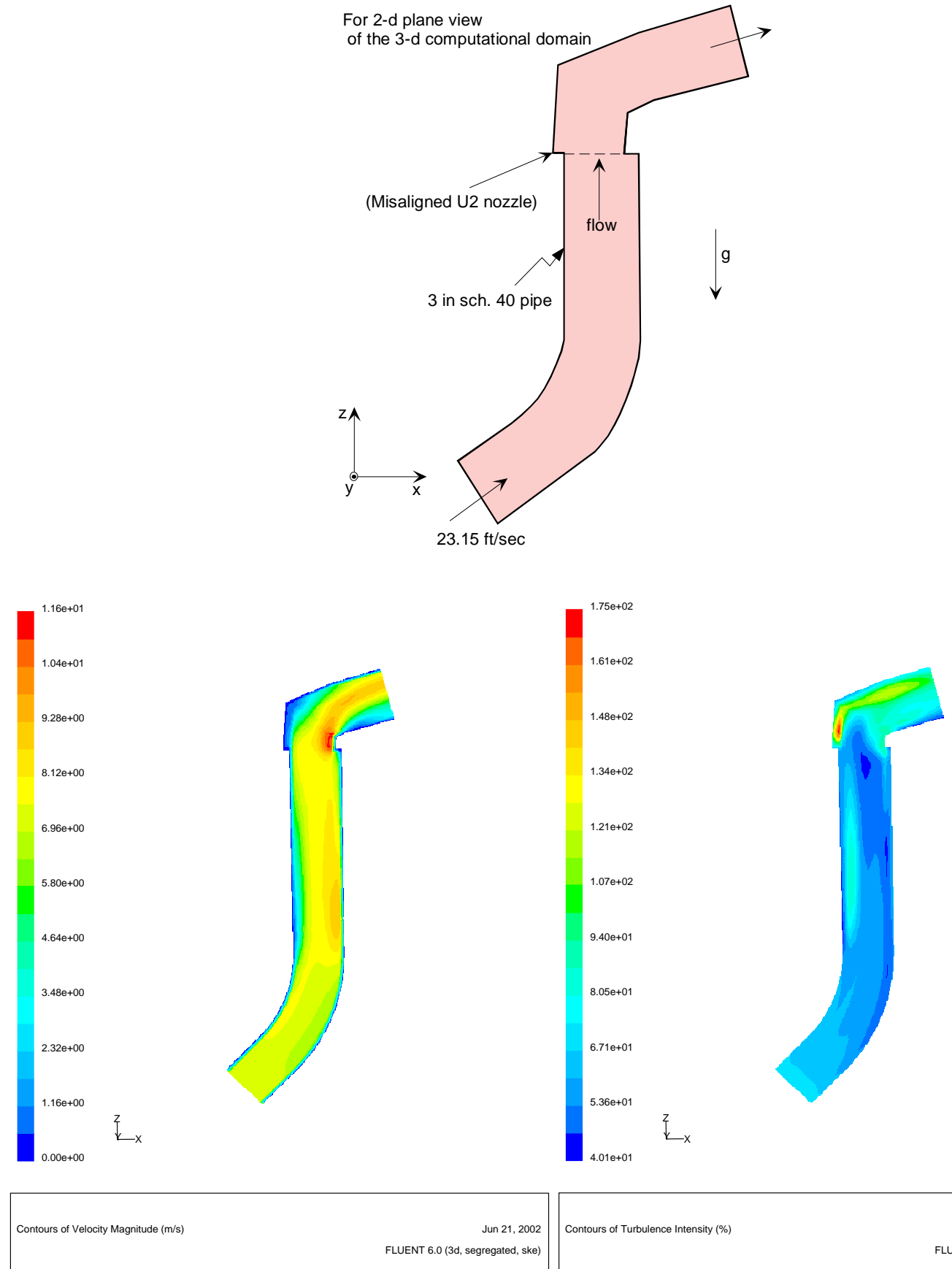

(Velocity distributions)

(Turbulence intensity)

Figure 11. Velocity and turbulence distributions at the center plane of the misaligned u2 nozzle component in a $3 \mathrm{H}$ evaporator steam lift system (The bottom side of the lift system shown above is fluid inlet.). 

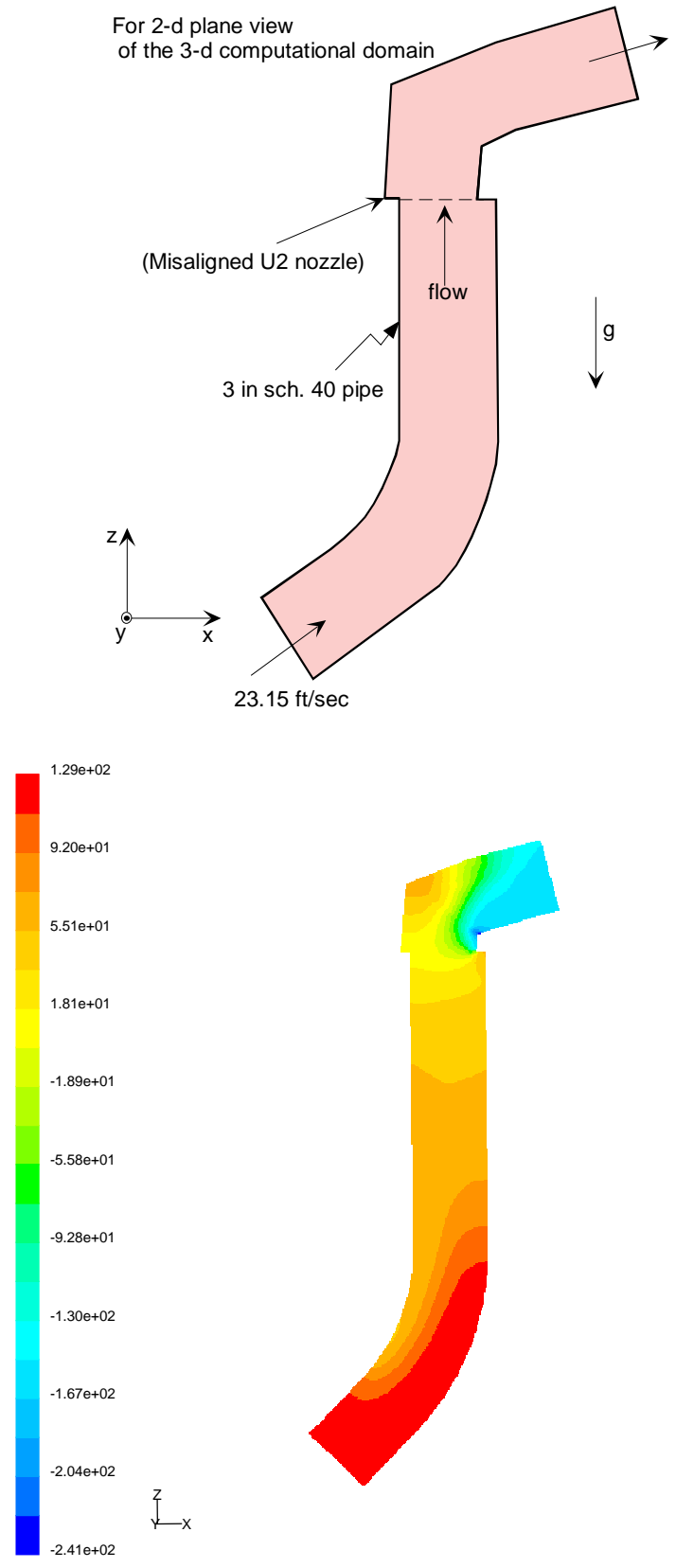

Figure 12. Pressure distributions at the center plane of the misaligned $u 2$ nozzle component in a $3 \mathrm{H}$ evaporator steam lift system (The bottom side of the lift system shown above is fluid inlet.). 
Report: WSRC-TR-2002-00352

Date: $\quad 10 / 21 / 02$

Page: $\quad 34$ of 56
WESTINGHOUSE SAVANNAH RIVER COMPANY

EROSION ANALYSIS FOR THE MISALIGNED U2 NOZZLE AND ITS CONNECTOR BLOCK

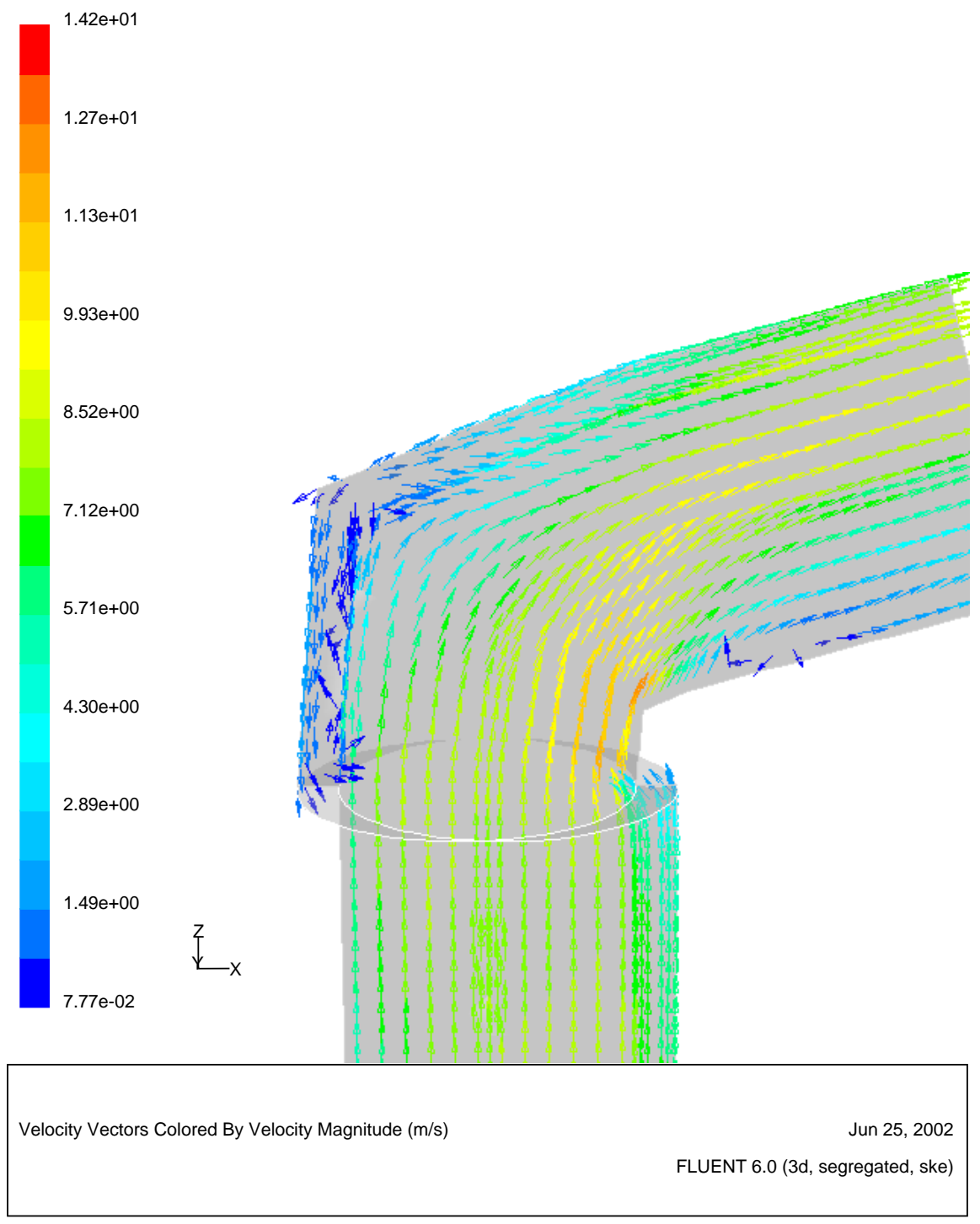

Figure 13. Velocity flow patterns at the mid-plane of the misaligned U2 nozzle 


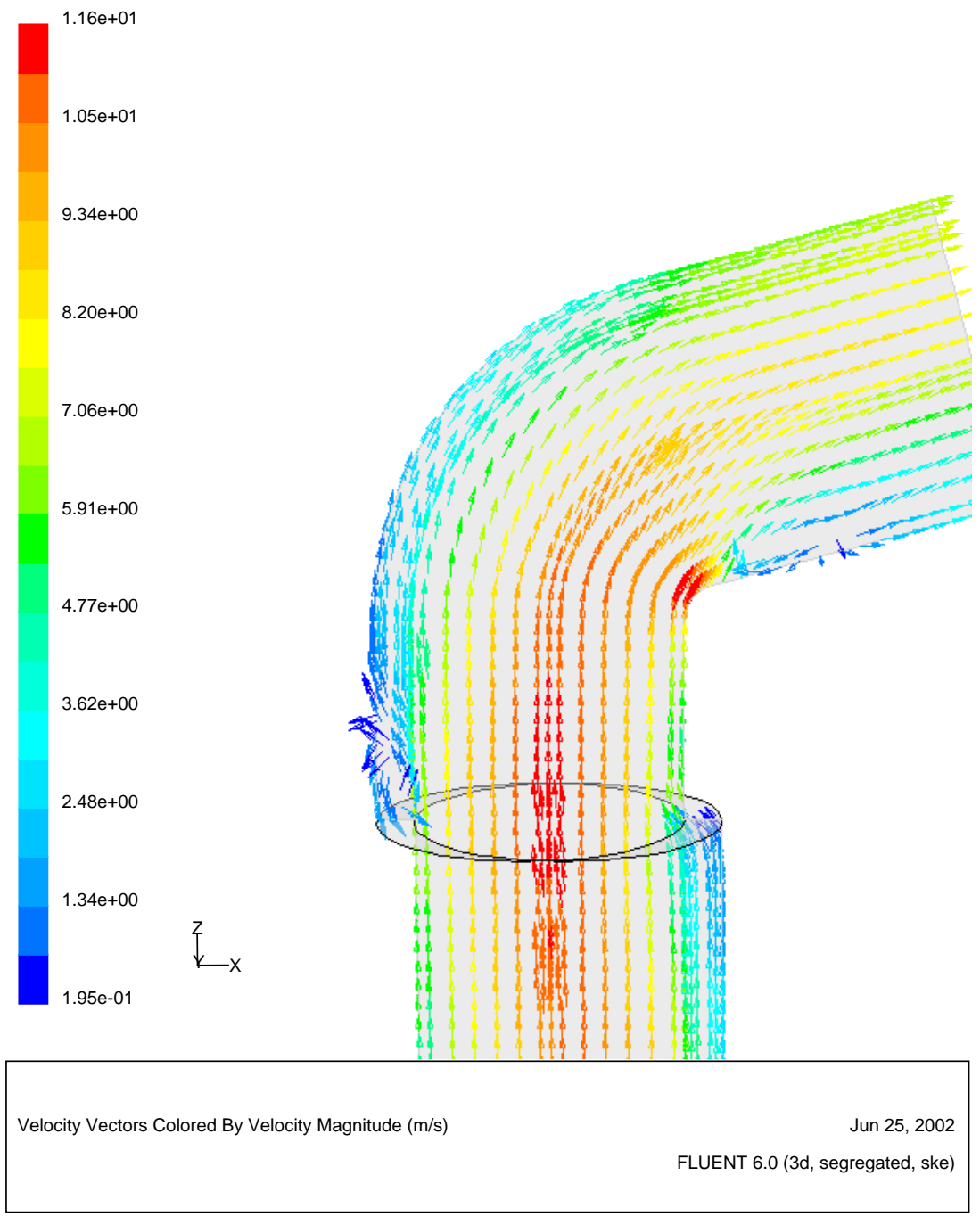

Figure 14. Velocity flow patterns at the mid-plane of the misaligned U2 nozzle in case of a smooth U2 nozzle connector 


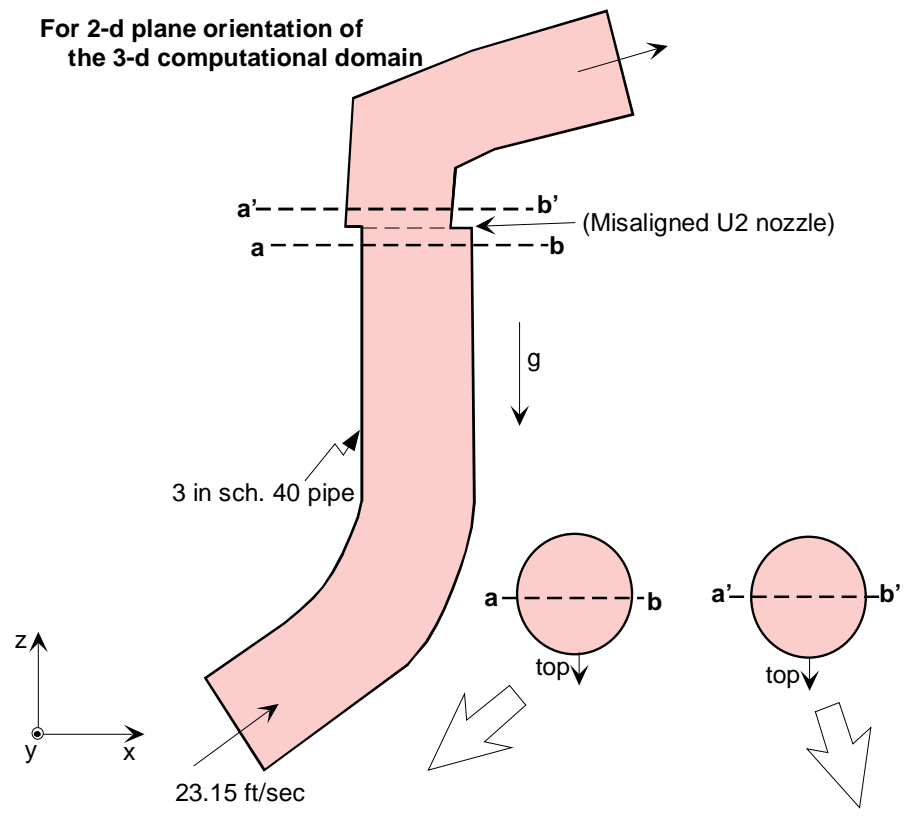

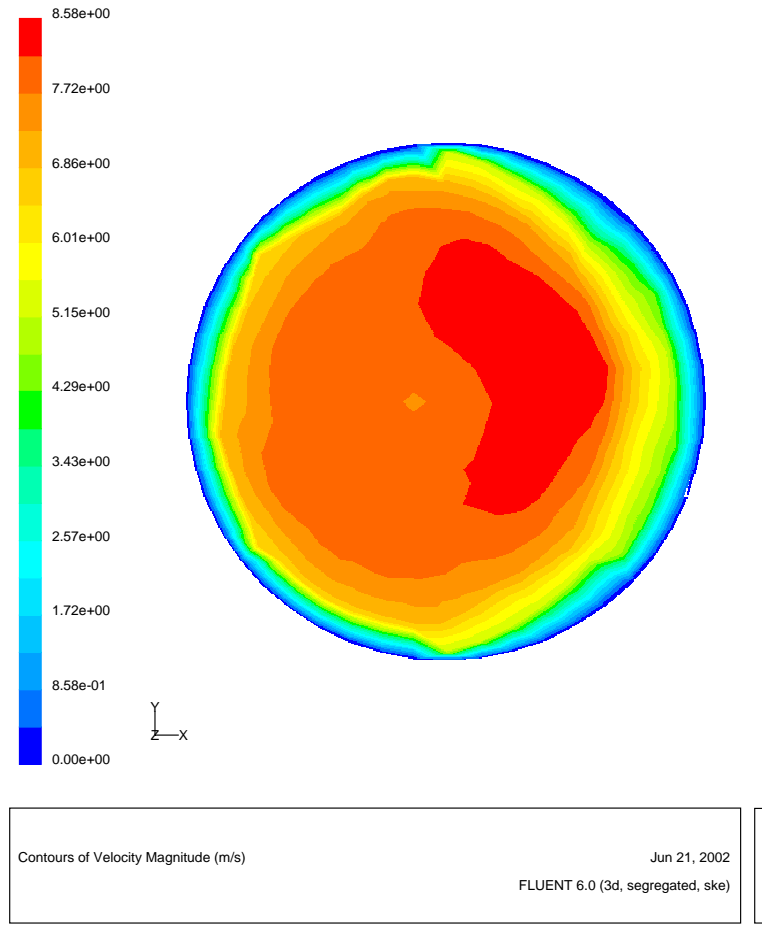

(U2 nozzle upstream)
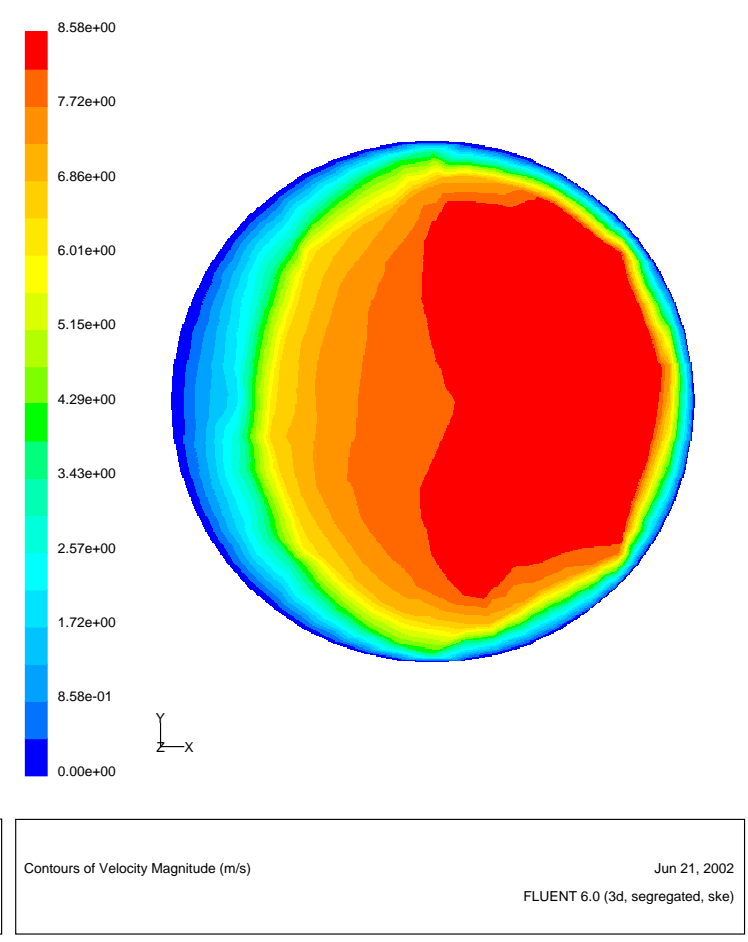

(U2 nozzle downstream)

Figure 15. Radial velocity distributions at the cross-sectional planes of the upstream and downstream regions of the misaligned U2 nozzle. 


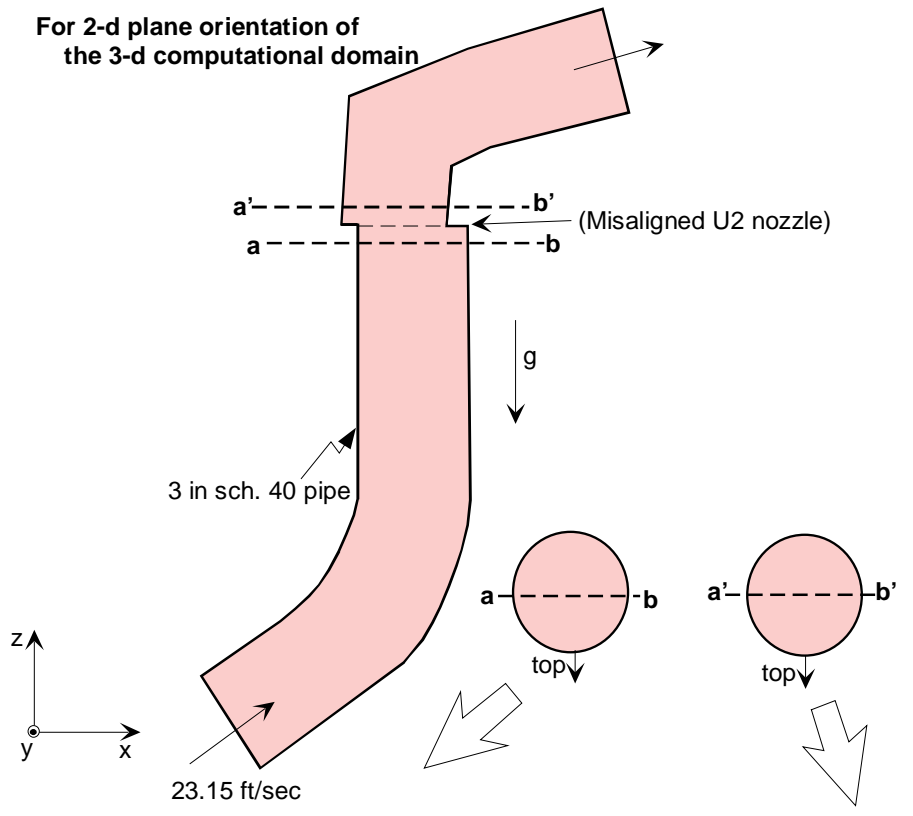

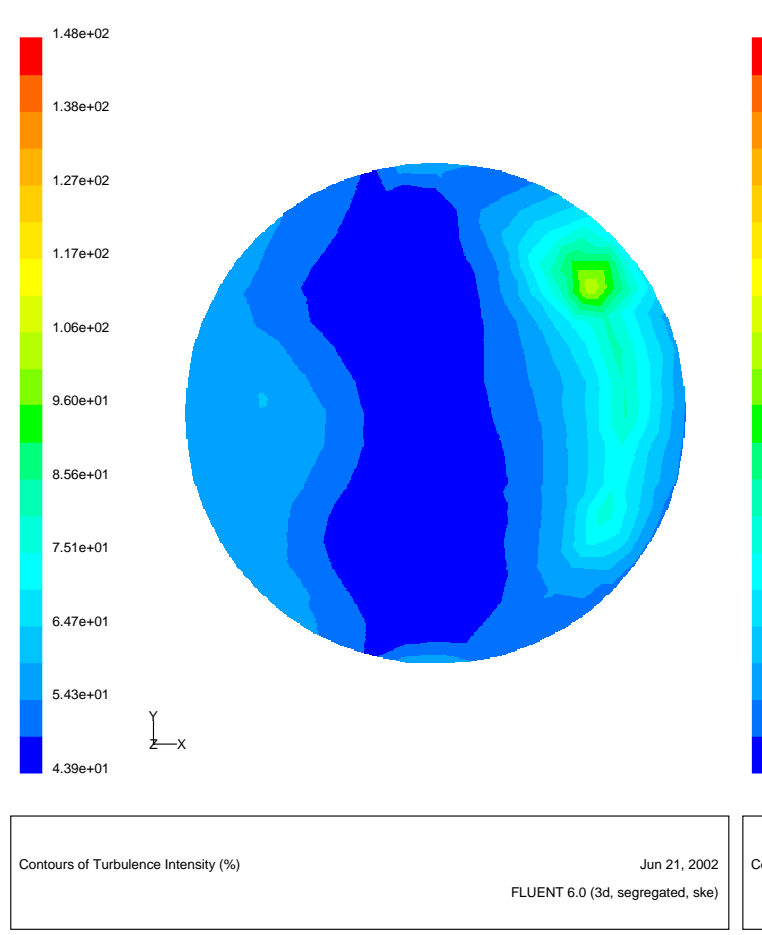

(elbow upstream)
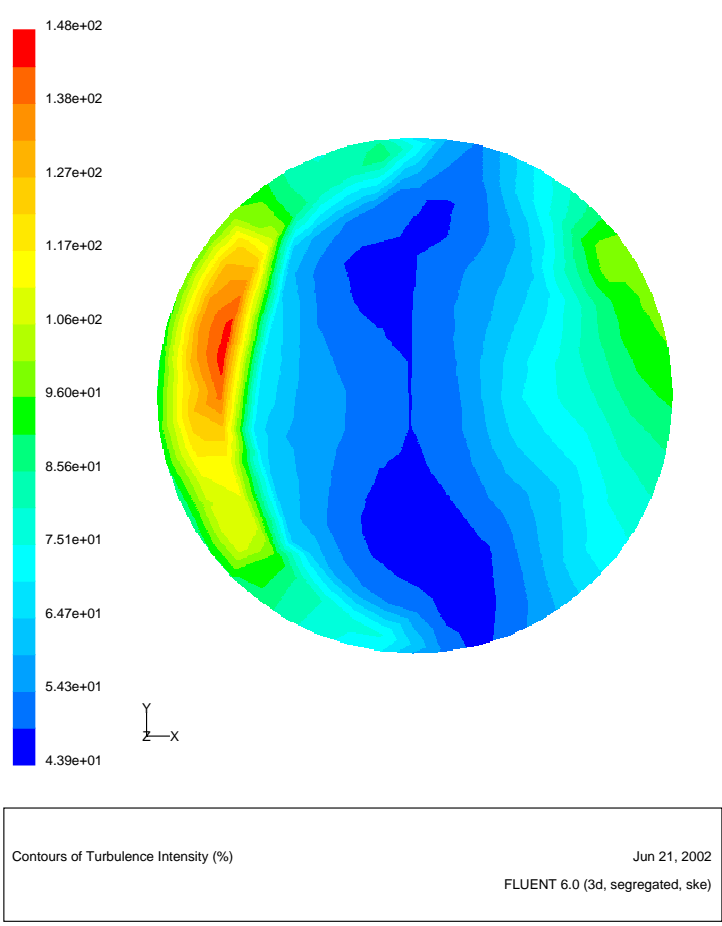

(elbow downstream)

Figure 16. Turbulence intensities at the cross-sectional planes of the upstream and downstream regions of the misaligned U2 nozzle. 


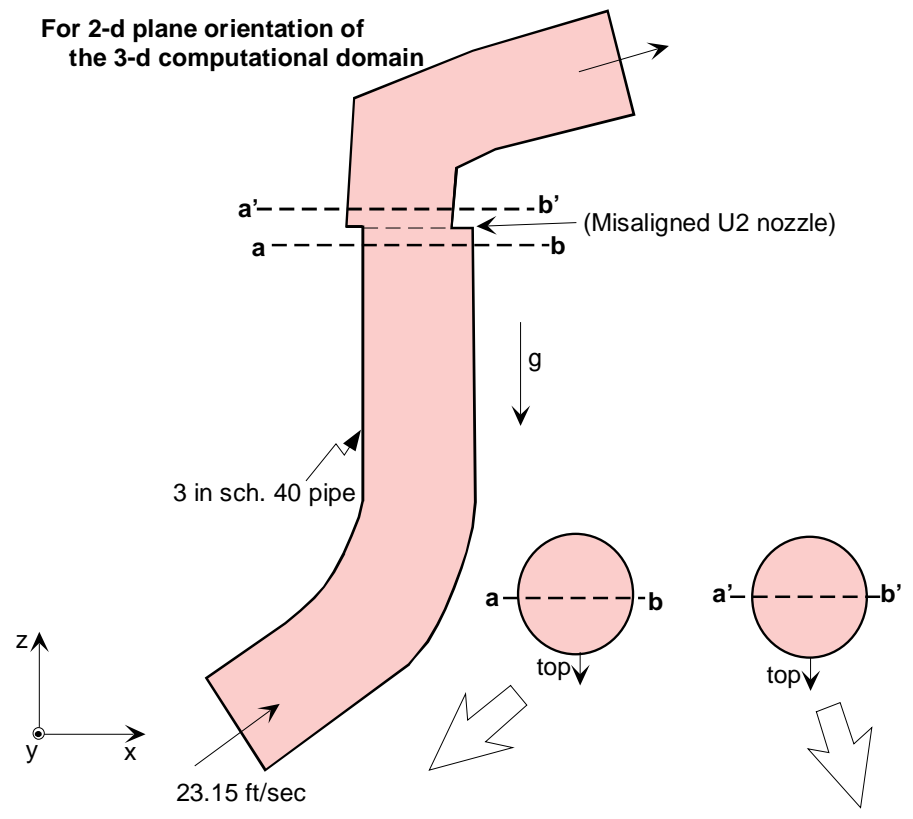

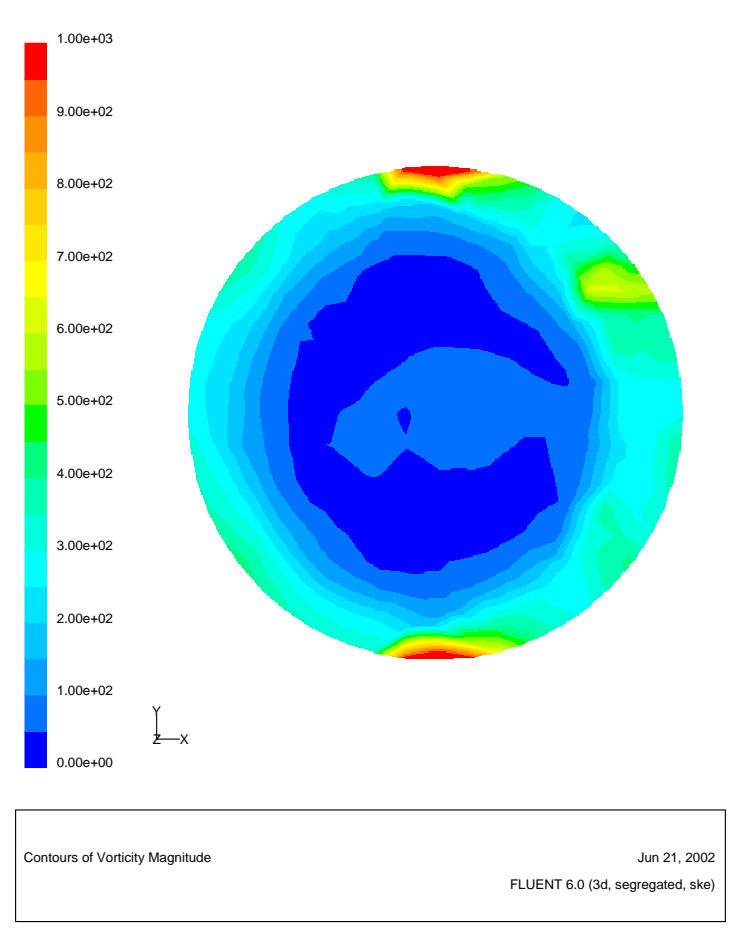

(U2 nozzle upstream)

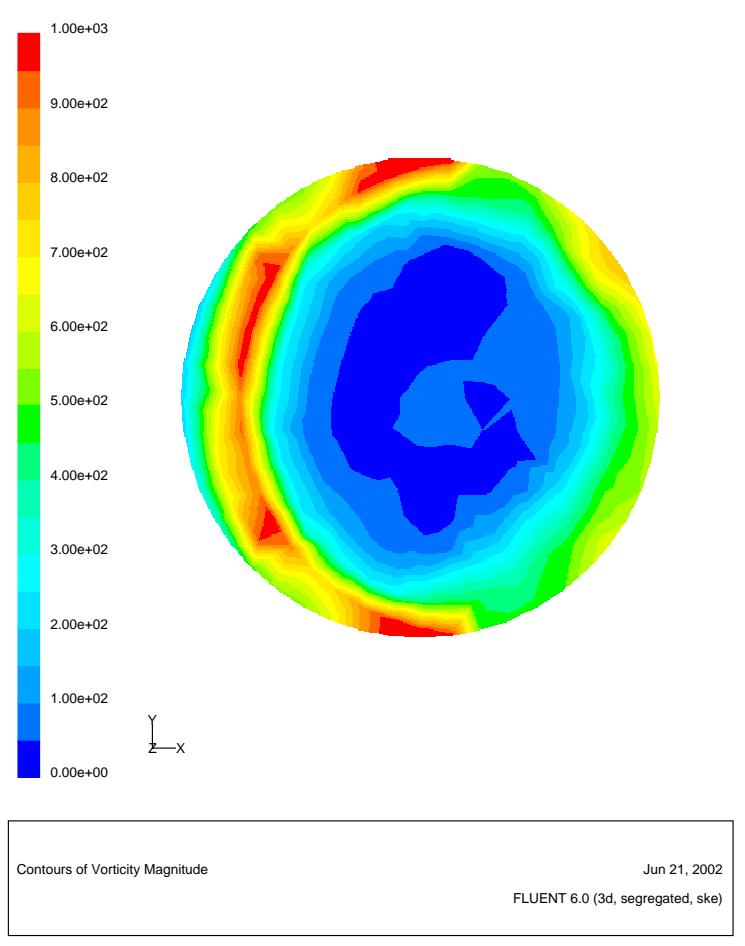

(U2 nozzle downstream)

Figure 17. Vorticity magnitudes at the cross-sectional planes of the upstream and downstream regions of the misaligned U2 nozzle. 

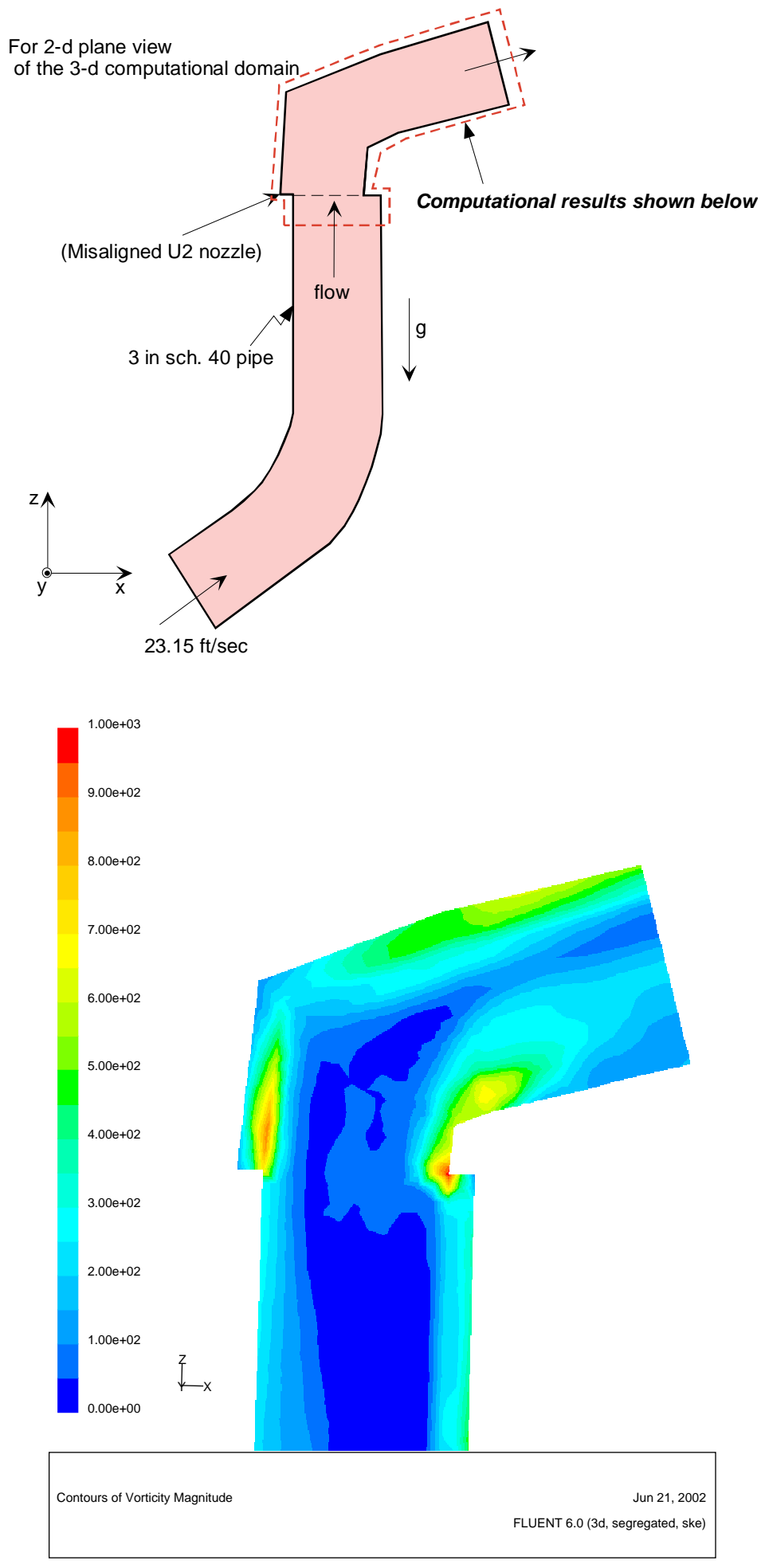

Figure 18. Vorticity magnitude distributions at the vertical center plane of the misaligned U2 nozzle. 
Report: WSRC-TR-2002-00352

Date: $\quad 10 / 21 / 02$

Page: $\quad 40$ of 56
WESTINGHOUSE SAVANNAH RIVER COMPANY

EROSION ANALYSIS FOR THE MISALIGNED U2 NOZZLE AND ITS CONNECTOR BLOCK

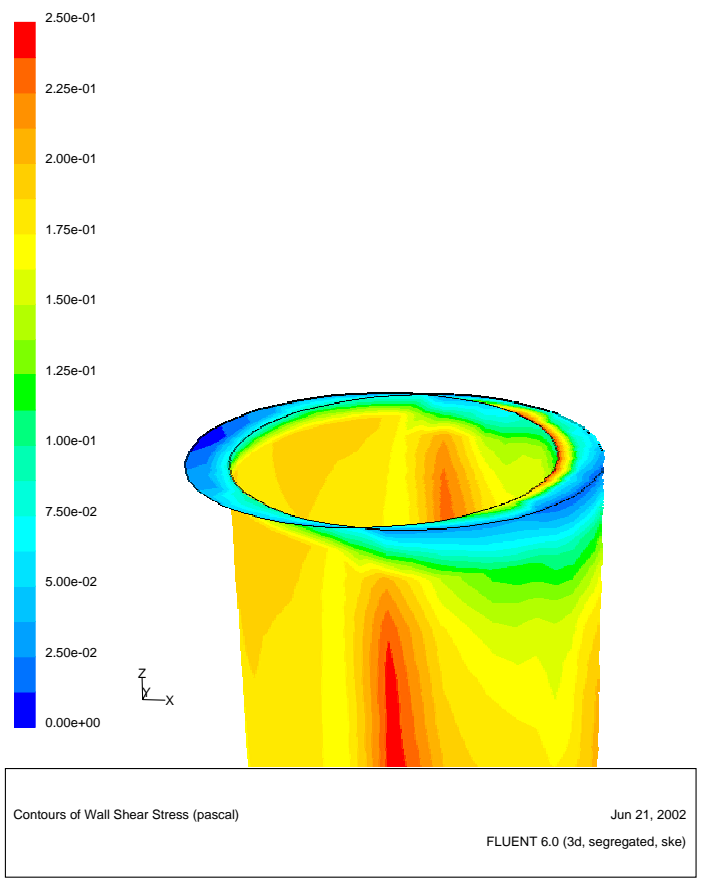

(upstream region of misaligned $\mathrm{U} 2$ nozzle)

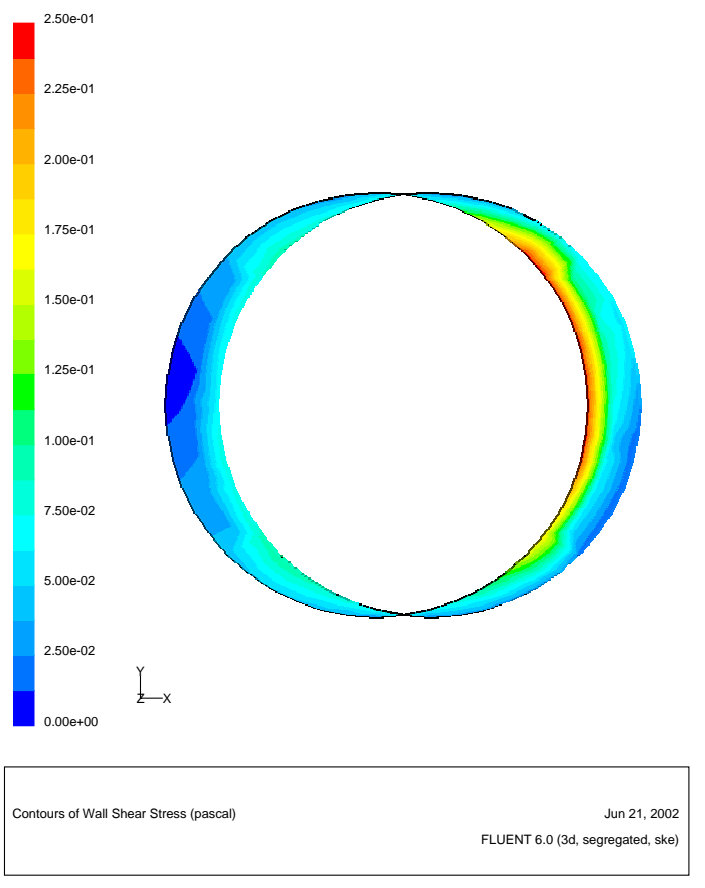

(misaligned wall surface of U2 nozzle)

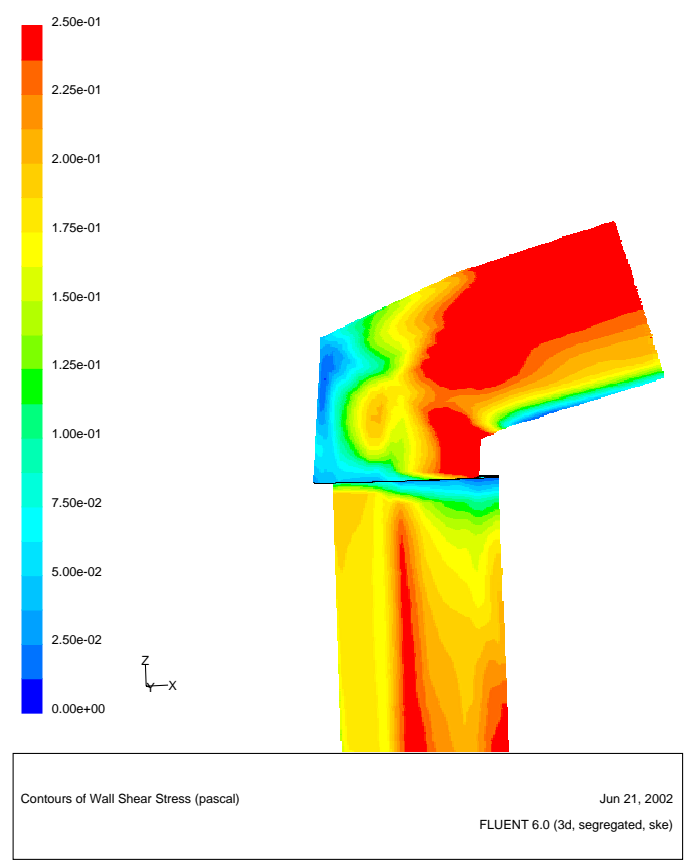

(upstream and downstream regions of the misaligned U2 nozzle)

Figure 19. Wall shear stress distributions for a slurry flow driven by steam flow in $3 \mathrm{H}$ evaporator steam lift jumper. 


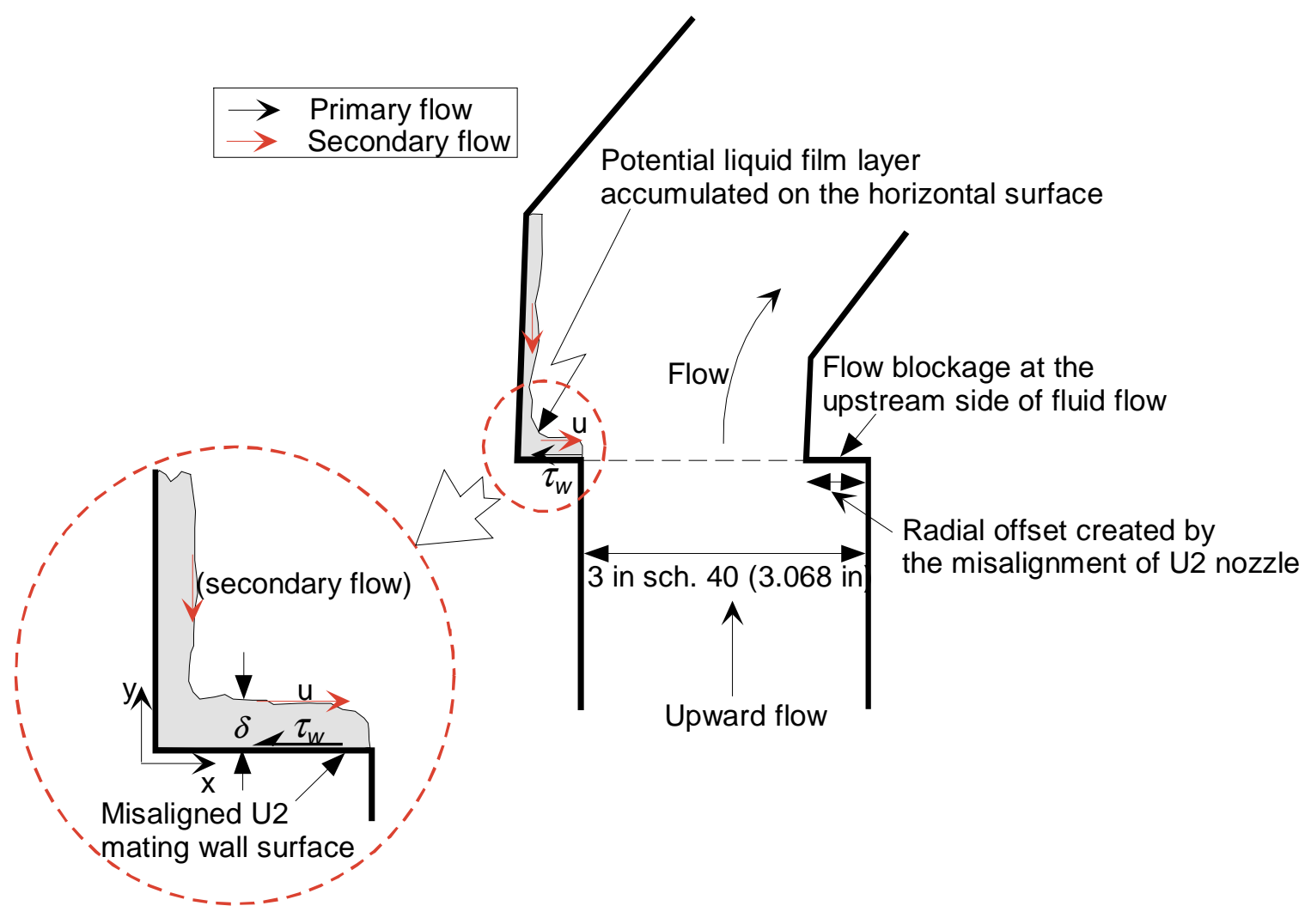

Figure 20. Erosion mechanisms for the misaligned U2 nozzle mating surfaces due to the abrasive wall shear and particle impingement of waste droplets in a steam flow for $3 \mathrm{H}$ evaporator steam lift jumper. 
Date: $\quad 10 / 21 / 02$ EROSION ANALYSIS FOR THE MISALIGNED U2 NOZZLE

Page: $\quad 42$ of 56 AND ITS CONNECTOR BLOCK

Table 7. Maximum shear stresses and relative maximum erosion rates for the upstream and downstream regions of the misaligned U2 nozzle under the reference conditions

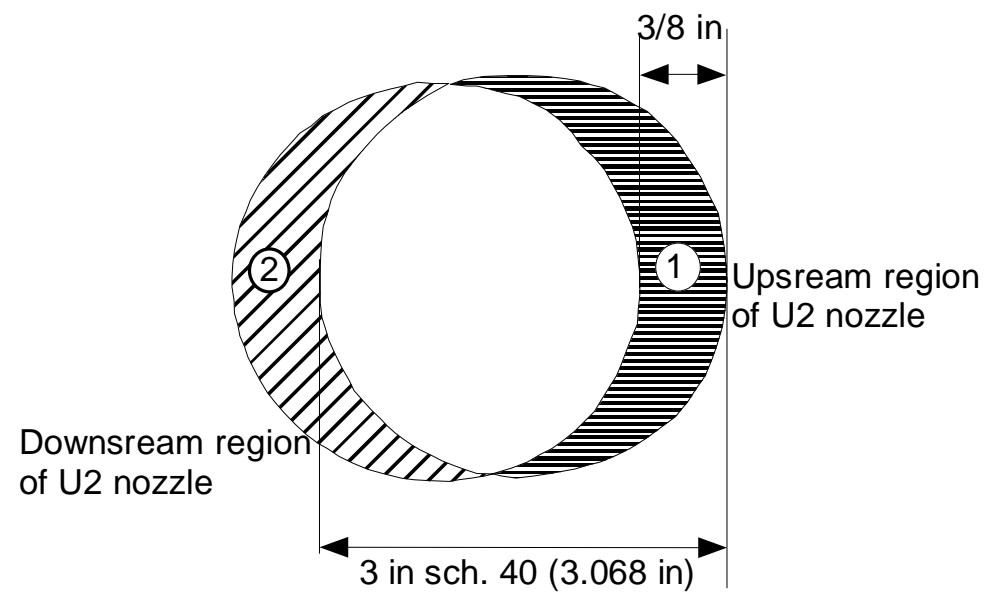

\begin{tabular}{|c|c|c|}
\hline $\begin{array}{c}\text { Locations of misaligned } \\
\text { U2 nozzle }\end{array}$ & $\begin{array}{c}\text { Upstream of U2 nozzle } \\
\text { (Region 1 as shown above) }\end{array}$ & $\begin{array}{c}\text { Downstream of U2 nozzle } \\
\text { (Region 2 as shown above) }\end{array}$ \\
\hline Flowrate & $\begin{array}{c}533.5 \mathrm{gpm} \text { (steam) } \\
25 \mathrm{gpm} \text { (waste) }\end{array}$ & $\begin{array}{c}533.5 \mathrm{gpm} \text { (steam) } \\
25 \mathrm{gpm} \text { (waste) }\end{array}$ \\
\hline $\begin{array}{c}\text { Pipe diameter } \\
\text { (3-in Sch. 40) }\end{array}$ & $3.068 \mathrm{in}$ & $3.068 \mathrm{in}$ \\
\hline $\begin{array}{c}\text { Max. wall shear causing } \\
\text { abrasive erosion }\end{array}$ & $0.32 \mathrm{~Pa}$ & $35 \mathrm{~Pa}$ * \\
\hline $\begin{array}{c}\text { Relative scale for max. } \\
\text { erosion due to droplet } \\
\text { impingement }\end{array}$ & 1.0 & $\sim 0.06$ \\
\hline
\end{tabular}

Note: * Computed by Eq. (13) using the boundary layer approximations 

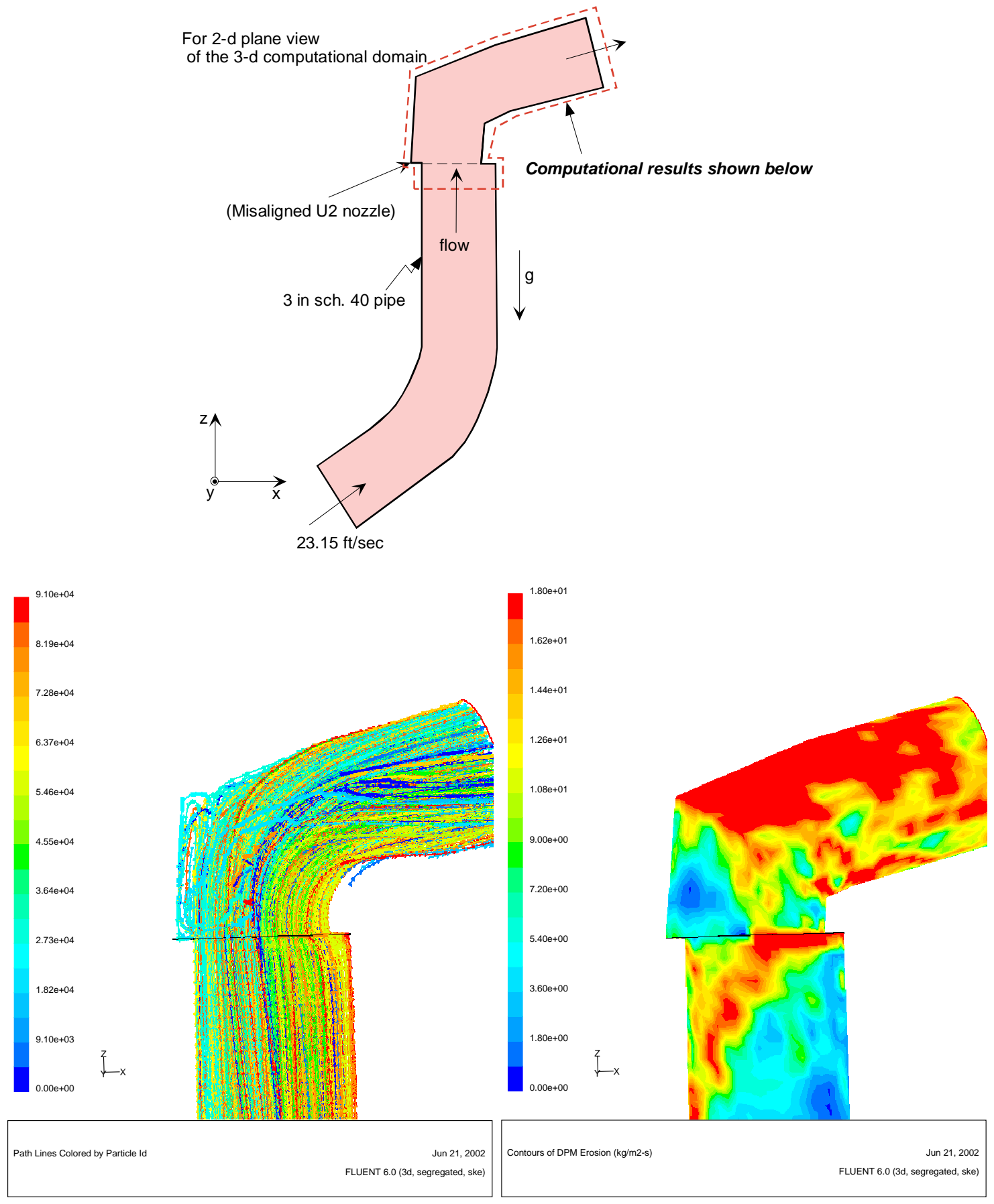

(particle trajectory)

(erosion distributions)

Figure 21. Particle trajectory and erosion distributions due to the impingement of waste droplets in a steam flow. 

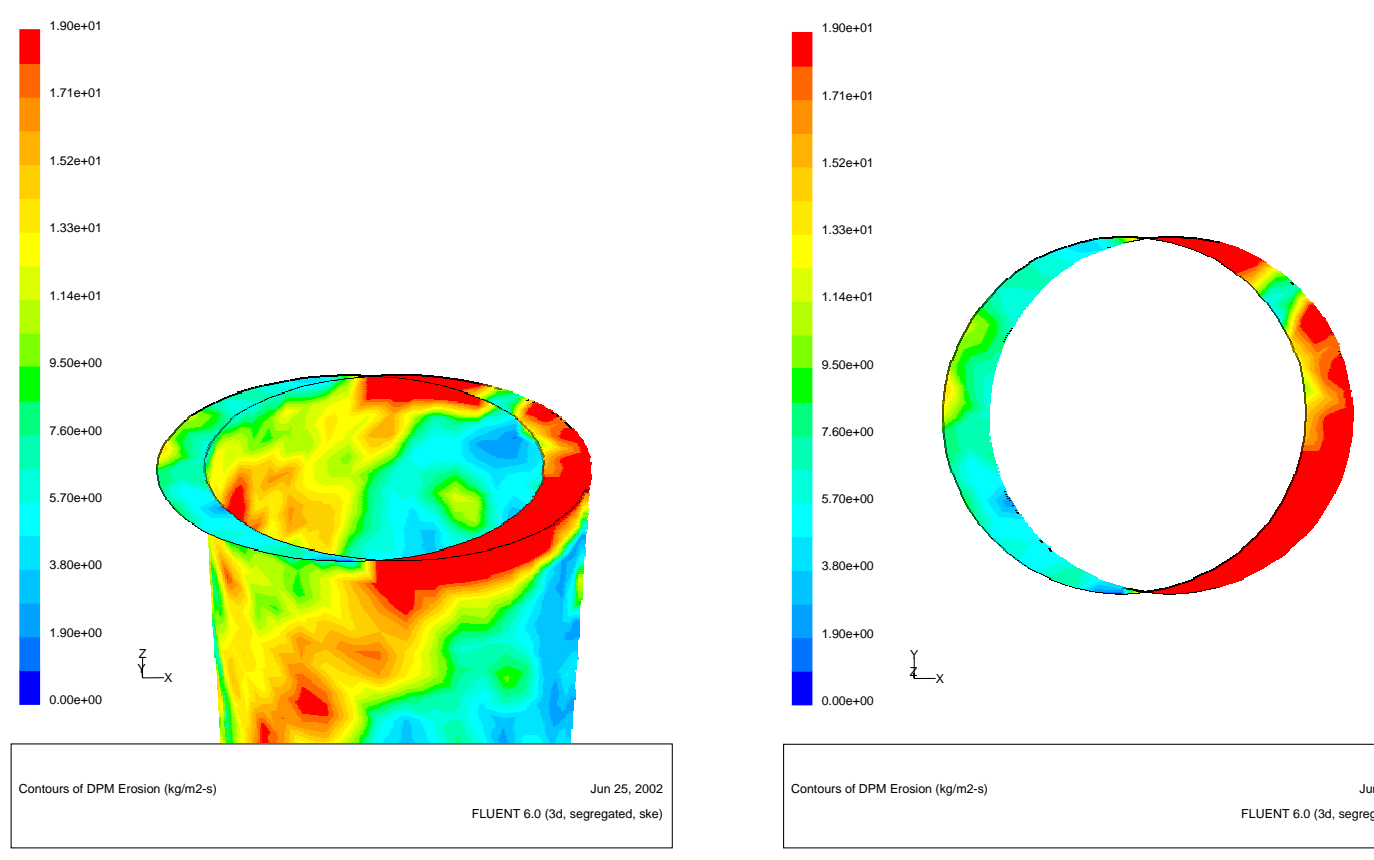

(upstream region of misaligned U2 nozzle) (misaligned wall surface of U2 nozzle)

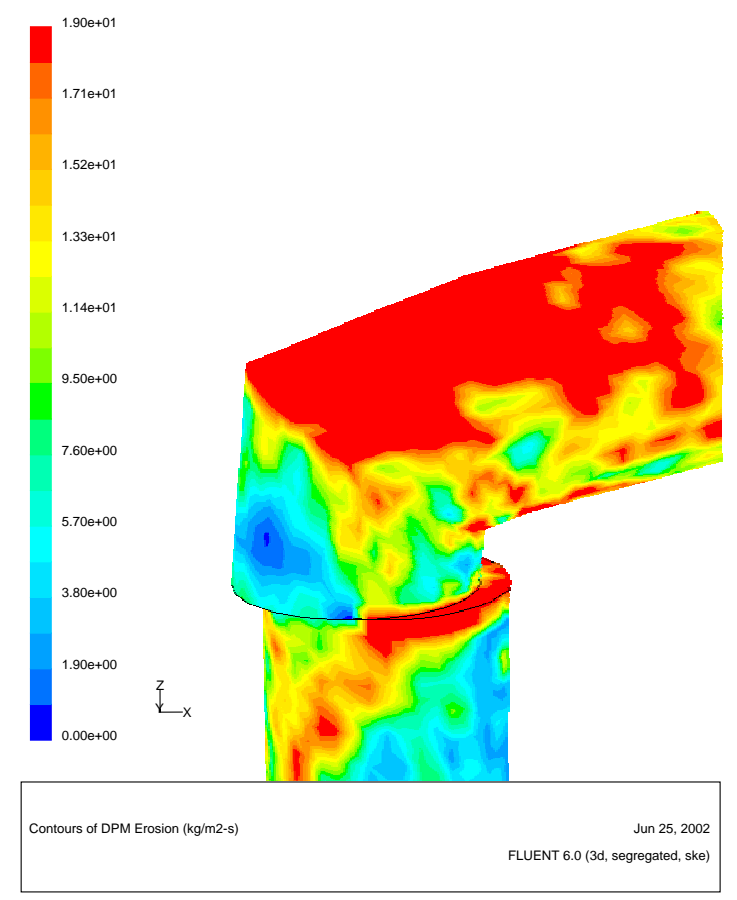

(upstream and downstream regions of the misaligned U2 nozzle)

Figure 22. Erosion distributions due to the particle impingement of waste droplets driven by steam flow in $3 \mathrm{H}$ evaporator steam lift jumper. 


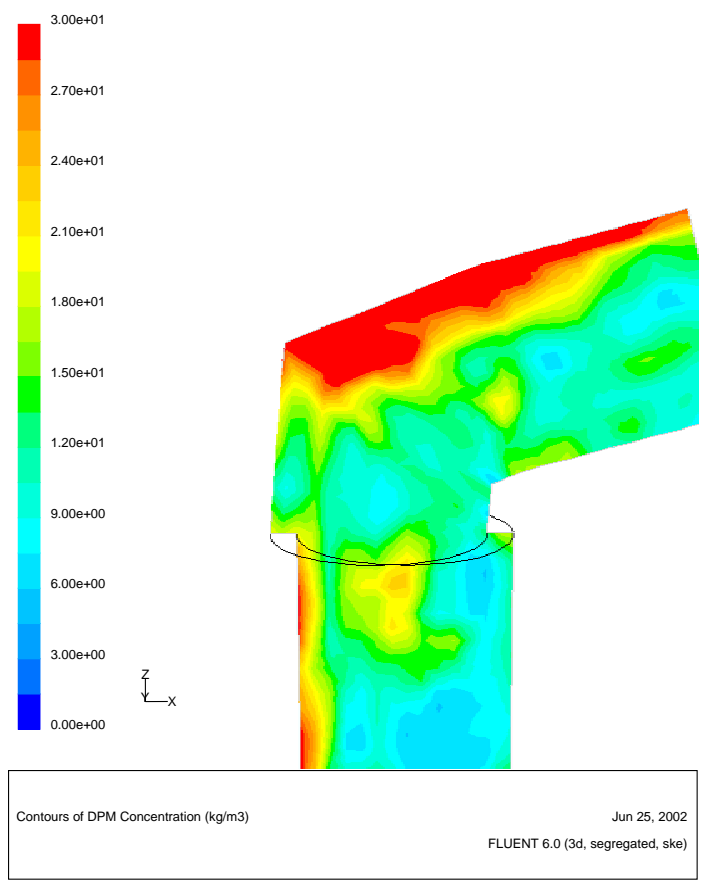

(Vertical mid-plane of the steam lift jumper system)

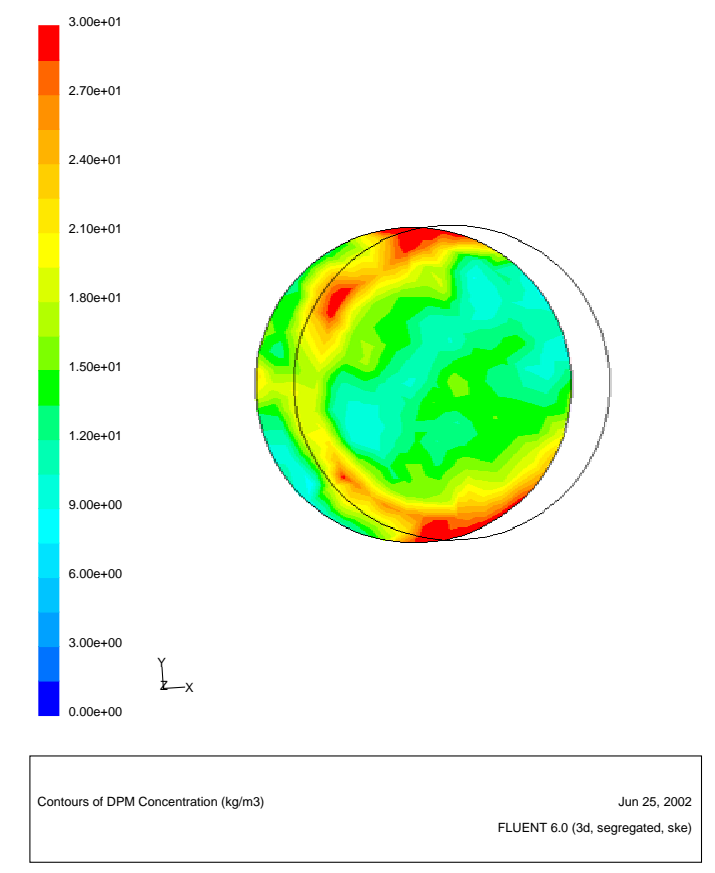

(Horizontal misaligned plane of the U2 nozzle downstream side)

Figure 23. Dispersed waste droplet distributions for a steam-driven flow. 
Date: $\quad 10 / 21 / 02$

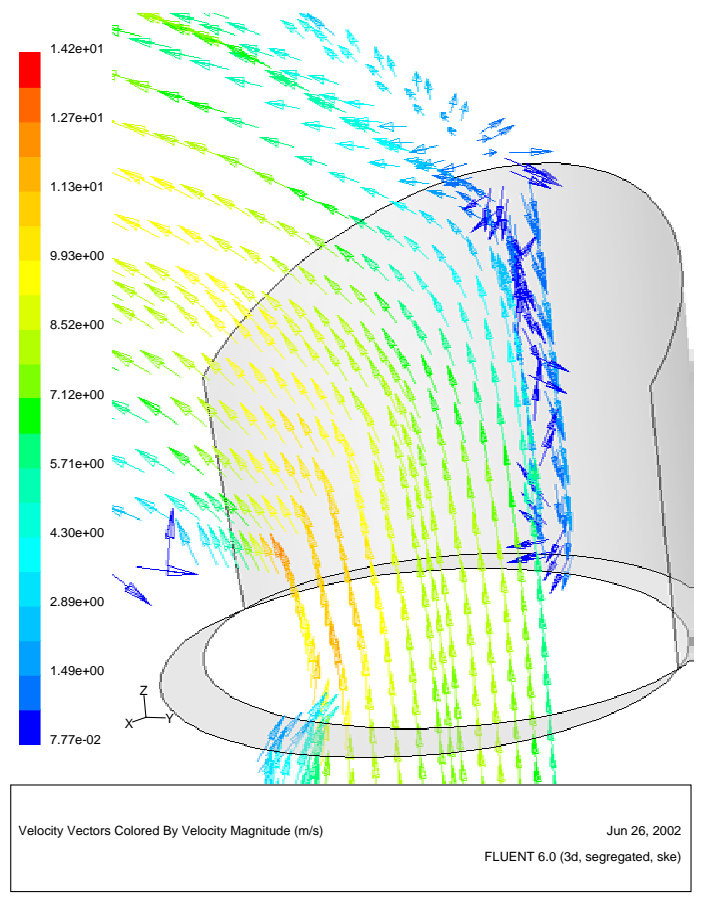

Figure 24. Flow patterns for the upstream region of the misaligned U2 nozzle showing secondary flow circulation near the wall surface of nozzle connector block.

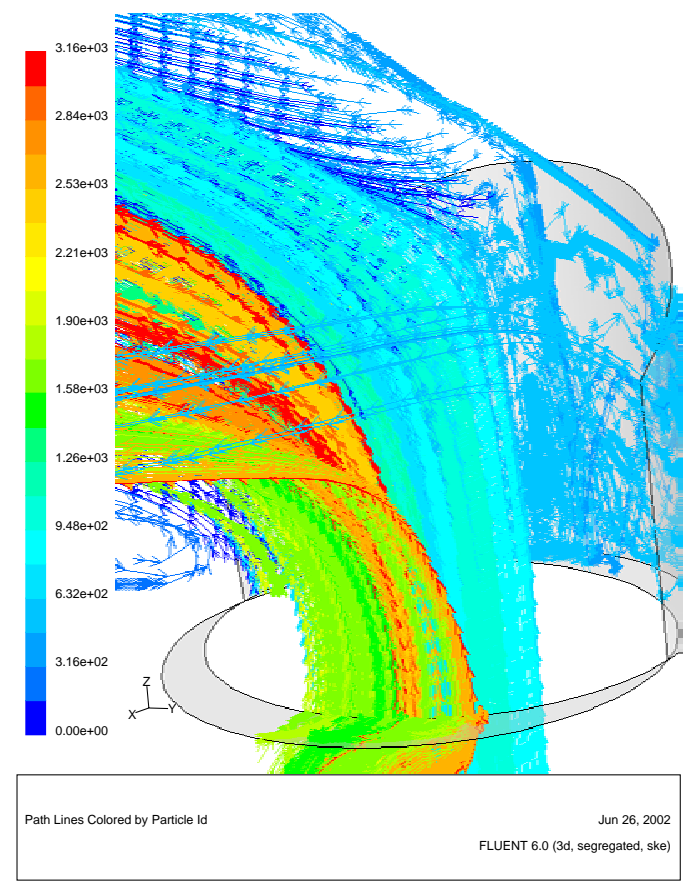

Figure 25. Particle paths released from the mid-plane of the steam lift jumper near the upstream region of the misaligned $U 2$ nozzle showing particle impingement on the misaligned horizontal surface due to the secondary flow circulation. 
Flow rotation due to secondary flow

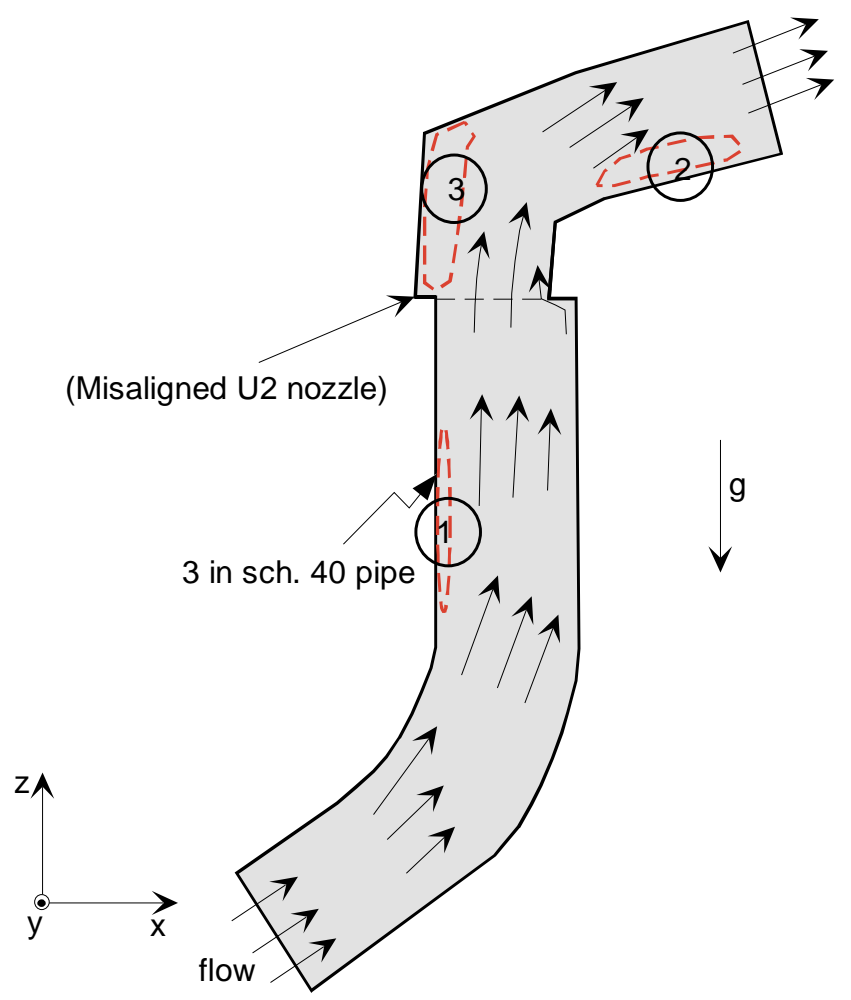

\begin{tabular}{|l}
\hline 2 Secondary flow rotations generated from the flow direction change \\
near pipe bend
\end{tabular}

Figure 26. Flow patterns associated with particle impingement of waste droplets for $3 \mathrm{H}$ evaporator lift jumper with misaligned U2 nozzle. 
(-) Potential max. abrasive erosion location due to high wall shear of a thin waste film layer

- Potential high abrasive erosion location due to the wall shear

( ) Potential high flow fluctuation location due to the turbulent flow

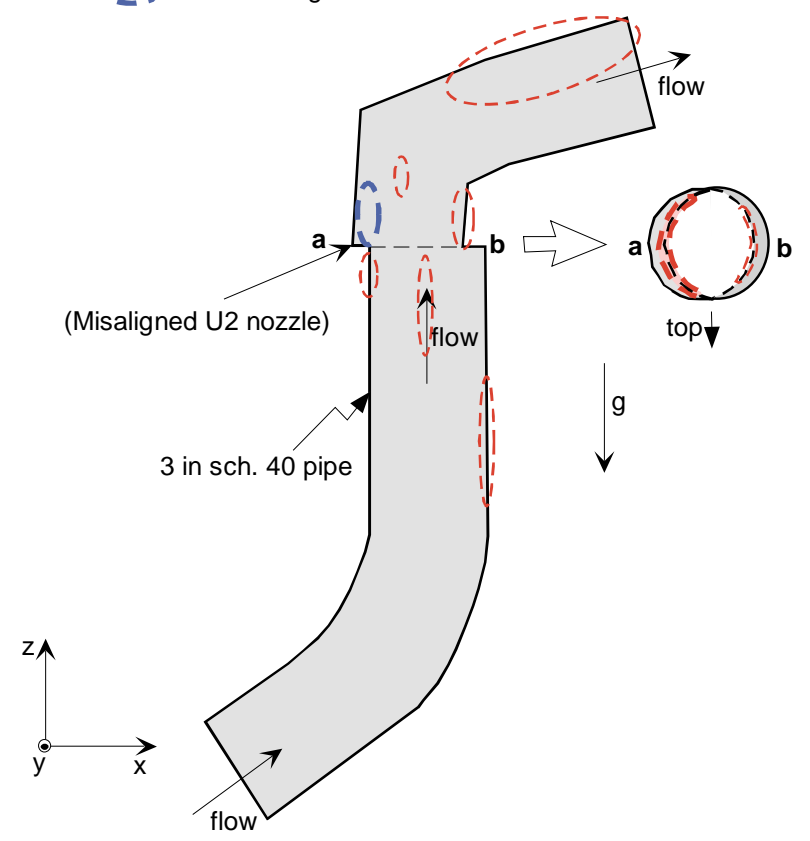

Figure 27. Potential abrasive erosion locations near the misaligned U2 nozzle of $3 \mathrm{H}$ evaporator steam lift jumper system due to the wall shear stress.

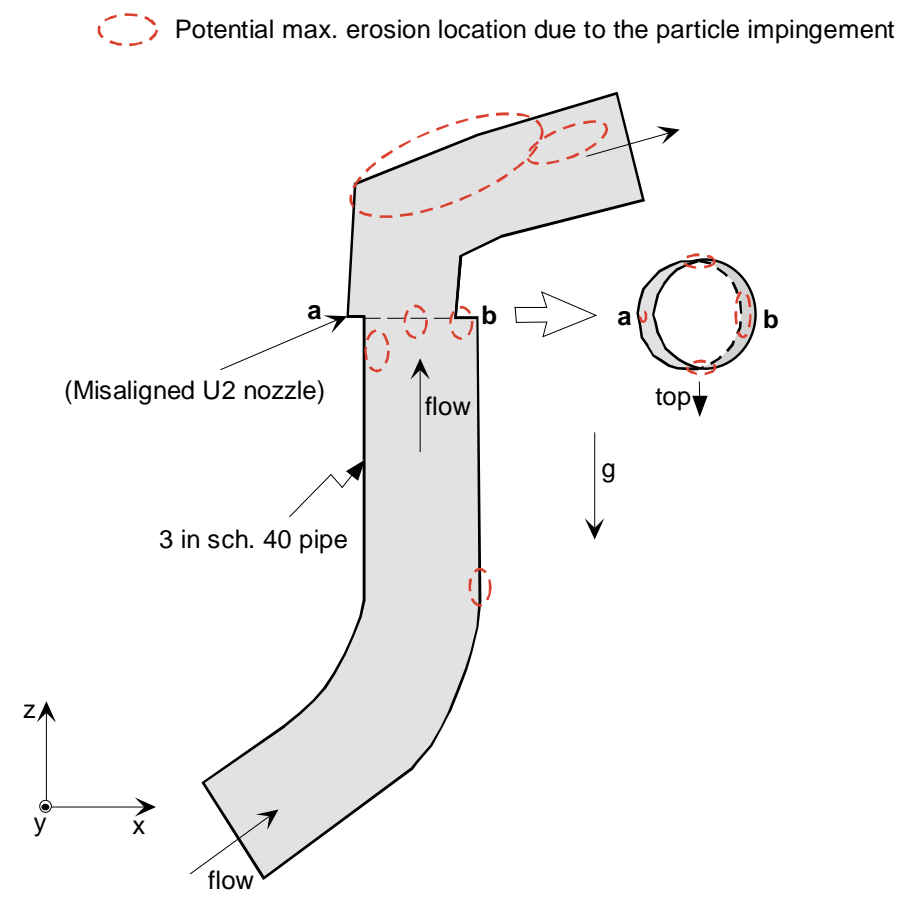

Figure 28. Potential erosion locations near the misaligned U2 nozzle of $3 \mathrm{H}$ evaporator steam lift jumper system due to the impingement of waste droplets in a steam flow. 
Table 8. Maximum shear stresses and relative maximum erosion rates on the misaligned mating surfaces for the two different radial offset sizes created by the U2 nozzle misalignment

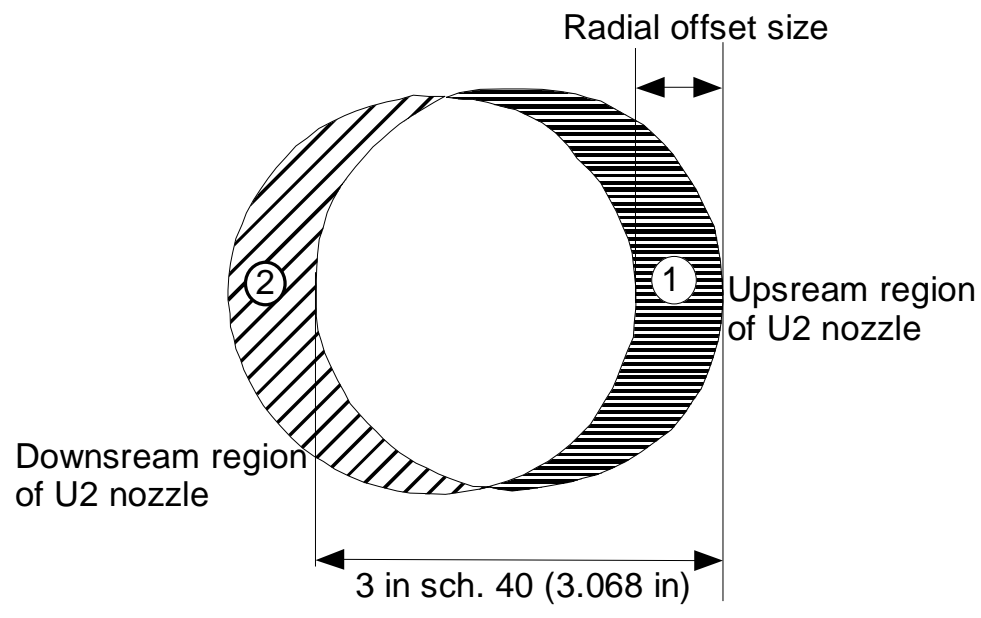

\begin{tabular}{|c|c|c|}
\hline $\begin{array}{c}\text { Radial offset size created by } \\
\text { the U2 nozzle misalignment }\end{array}$ & $\begin{array}{c}3 / 8 \text { in } \\
\text { (reference condition) }\end{array}$ & $3 / 16$ in \\
\hline Flowrate & $\begin{array}{c}533.5 \mathrm{gpm} \text { (steam) } \\
25 \mathrm{gpm} \text { (waste) }\end{array}$ & $\begin{array}{c}533.5 \mathrm{gpm} \text { (steam) } \\
25 \mathrm{gpm} \text { (waste) }\end{array}$ \\
\hline $\begin{array}{c}\text { Pipe diameter } \\
\text { (3-in Sch. 40) }\end{array}$ & $3.068 \mathrm{in}$ & $3.068 \mathrm{in}$ \\
\hline $\begin{array}{c}\text { Pressure drop } \\
\text { between inlet and exit }\end{array}$ & $274(\mathrm{~Pa})$ & $214(\mathrm{~Pa})$ \\
\hline $\begin{array}{c}\text { Pressure drop across the } \\
\text { misaligned U2 nozzle }\end{array}$ & $47(\mathrm{~Pa})$ & 15 (Pa) \\
\hline $\begin{array}{c}\text { Max. wall shear causing } \\
\text { abrasive erosion }\end{array}$ & $\begin{array}{c}0.32 \mathrm{~Pa} \text { (Region 1), } \\
35 \mathrm{~Pa}^{*}(\mathrm{Region} 2)\end{array}$ & $\begin{array}{c}0.28 \mathrm{pa} \text { (Region 1), } \\
35 \mathrm{~Pa} \text { * (Region 2) }\end{array}$ \\
\hline $\begin{array}{c}\text { Relative scale for max. erosion } \\
\text { due to droplet impingement }\end{array}$ & 1.0 & $\sim 0.2$ \\
\hline
\end{tabular}

Note: * Computed by Eq. (13) using the boundary layer approximations 
Report: WSRC-TR-2002-00352

Date: $\quad 10 / 21 / 02$

Page: $\quad 50$ of 56
WESTINGHOUSE SAVANNAH RIVER COMPANY

EROSION ANALYSIS FOR THE MISALIGNED U2 NOZZLE AND ITS CONNECTOR BLOCK

Table 9. Maximum shear stresses and relative maximum erosion rates on the misaligned mating surfaces of the misaligned U2 nozzle mating surfaces for the two different designs of U2 nozzle connector

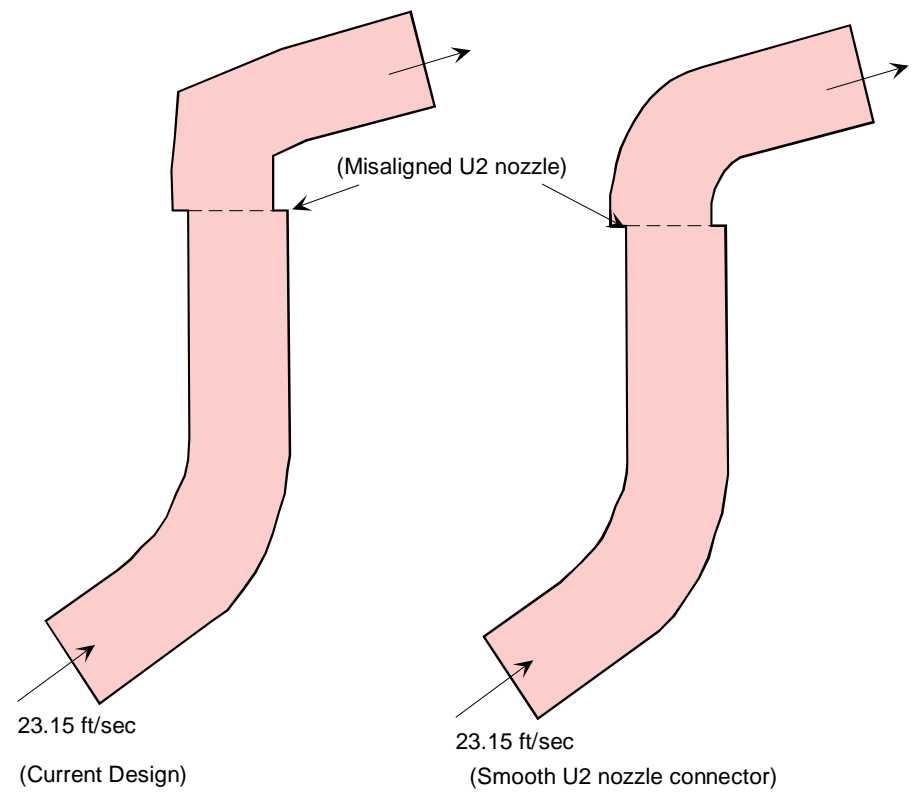

\begin{tabular}{|c|c|c|}
\hline $\begin{array}{c}\text { U2 nozzle connector } \\
\text { design }\end{array}$ & Current U2 nozzle connector & Smooth U2 nozzle connector \\
\hline Flowrate & $\begin{array}{c}533.5 \mathrm{gpm} \text { (steam) } \\
25 \mathrm{gpm} \text { (waste) }\end{array}$ & $\begin{array}{c}533.5 \mathrm{gpm} \text { (steam), } \\
25 \mathrm{gpm} \text { (waste) }\end{array}$ \\
\hline $\begin{array}{c}\text { Pipe diameter } \\
\text { (3-in Sch. 40) }\end{array}$ & 3.068 in & 3.068 in \\
\hline $\begin{array}{c}\text { Radial offset size } \\
\text { created by nozzle } \\
\text { misalignment }\end{array}$ & $3 / 8$ in & $3 / 8$ in \\
\hline $\begin{array}{c}\text { Pressure drop } \\
\text { between inlet and exit }\end{array}$ & 274 (Pa) & 199 (Pa) \\
\hline $\begin{array}{c}\text { Max. wall shear } \\
\text { causing abrasive } \\
\text { erosion }\end{array}$ & $\begin{array}{c}0.32 \mathrm{~Pa} \text { (upstream region), } \\
\text { (downstream region) }\end{array}$ & $\begin{array}{c}0.23 \mathrm{~Pa} \text { (upstream region), } \\
\text { (downstream region) }\end{array}$ \\
\hline $\begin{array}{c}\text { Relative scale for max. } \\
\text { erosion due to droplet } \\
\text { impingement }\end{array}$ & 1.0 & $\sim 0.9$ \\
\hline
\end{tabular}

Note: * Computed by Eq. (13) using the boundary layer approximations 


\section{Summary and Conclusions}

This report presents the application of computational fluid dynamics (CFD) methods to qualitative estimate of the erosion phenomena expected in the actual process facility. Using the transport equations governing the steam-slurry flow, two erosion mechanisms were considered to evaluate high erosion sites and to investigate the primary cause of wear damage for the modeling domain representative of the actual flow process in the U2 nozzle misalignment. One of the two erosion mechanisms is the abrasive erosion which is worn by high wall shear of viscous liquid film or by continuous contact or lowangle collision of the moving solids with rough surface, and the other is the chip-off erosion which is mainly governed by high-angle impingement of particles. As discussed earlier, ductile wall material such as Hastalloy G3 or stainless steel is damaged by both erosion mechanisms when particles are impinged on the ductile surface with low attack angle.

For the present work, Eulerian continuous transport equations for the steam flow and Lagrangian momentum balance for the liquid phase dispersed in the continuous steam flow were used to estimate wall shear and particle-impinged erosions. For typical operating conditions of the facility, Reynolds number is about $10^{5}$ corresponding to fully turbulent flow regime. Two-equation turbulence model was used to consider the dispersion effect of particles due to turbulent eddies. In the analysis, flow patterns, wall shear, turbulent intensity, and vorticity distributions were considered as the key parameters for capturing flow characteristics and providing information on potential failure sites caused by erosion damage. Based on the modeling domain defined in Fig. 2 and the operating conditions shown in Table 1 and Table 2, the erosion evaluations for two different offset sizes and two different types of nozzle connector blocks were performed to provide information on wear damage causes of the misaligned U2 nozzle mating surfaces.

Three sets of representative experiments were chosen to test the CFD models presented in this work. All these tests were performed using sand-water slurry. The benchmarking results against the literature data for hydraulic transport and erosion tests are reasonably good taking into account the complex nature of fluid-solid two-phase phenomena.

The results show:

1. The primary locations of high erosion due to particle impingement are at the occurrence of sudden change of flow direction, sudden contraction, and flow obstruction as expected.

2. Potential damage sites due to the abrasive wall erosion are at the upstream and downstream regions of a sudden change in flow direction.

3. The sharp corner in the elbow downstream of the nozzle junction enhances liquid separation from the mainstream and leads to an abrasive, viscous liquid layer developing on the downstream horizontal shelf formed by the misaligned nozzle. This layer significantly enhances erosion on the exposed downstream flange surface. 
Date: $\quad 10 / 21 / 02$

EROSION ANALYSIS FOR THE MISALIGNED U2 NOZZLE

Page: 52 of 56 AND ITS CONNECTOR BLOCK

These findings are consistent with the observed damage to the misaligned U2 nozzle. However, all the computational results for the erosion presented in this report were estimated qualitatively in terms of flow patterns and erosion characteristics. 


\section{References}

1. Chapman, N. F., "Engineering Plan to Identify Primary Cause of Evaporator Leaks in Lift-Separator Jumper", Interoffice Memorandum to W. F. Davis, HLW-STE-200200164, April 29, 2002.

2. Skidmore, T. E., " $3 \mathrm{H}$ Evaporator Lift Separator Jumper Failure - Preliminary Analysis (U)", Interoffice Memorandum to N. F. Chapman, SRT-MTS-2002-40056, Rev. 0, April 16, 2002.

3. Lee. S. Y. and Dimenna, R. A., "Design Analysis For A Scaled Erosion Test", WSRC-TR-2001-00591, SRT-RPP-2001-00227, Rev. 0, April 2002.

4. Duignan, M. R. and Lee, S. Y., "RPP-WTP Slurry Wear Evaluation: Literature Review", Savannah River Technology Center, WSRC-TR-2001-00156, SRT-RPP2001-00033, March 21, 2001.

5. Reference Drawings No. D-10616, Rev. 4 (done by Joseph Oat Corporation, NJ), and Engineering Drawings No. W2010909 (P-PA-H-5253, Rev. 3) Savannah River Site.

6. Wallis, G. B., One-Dimensional Two-Phase Flow, McGraw-Hill Book Company, New York, 1969.

7. Burstein, G. T. and Sasaki, K., Effect of impact angle on the slurry erosion-corrosion of 304L stainless steel. Wear 240, 80-94, 2000.

8. Finnie, I., "Some reflections on the past and future of erosion", Wear, vol. 186, pp. 110, 1995.

9. Anderson, R. J. and Russell, T. W. F., "Film Formation in Two-Phase Annular Flow", A. I. Ch. E. Journal, vol. 16, pp. 626, 1970.

10. FLUENT, Fluent, Inc., Lebanon, New Hampshire, 1998.

11. Foley, T. and Levy, A., "The erosion of heat-treated steels", Wear, vol. 91, pp. 4564, 1983.

12. Gandhi, B.K., Singh, S.N., and Seshadri, V., "Study of the parametric dependence of erosion wear for the parallel flow of solid-liquid mixtures", Tribology International, vol. 32, pp. 275-282, 1999.

13. Golcar, G.R., Brooks, K.P., Darab, J.G., Davis, J.M., and Jagoda, L.K., "Development of inactive high-level waste envelope D Simulant for scaled crossflow filtration testing", Battelle Pacific Northwest National Laboratory Report No. PNWD3042, 2000.

14. Graf, W. H., Hydraulics of Sediment Transport, McGraw-Hill Book Company, New York, 1971.

15. Hisamitsu, N., Iseh, T., and Takeishi, Y., "An experimental study on pipe erosion by sand slurry", Proc. $6^{\text {th }}$ Conference on Slurry Transportation, Slurry Transport Association, pp. 319-332, 1981.

16. Iwai, Y. and Nambu, K., "Slurry wear properties of pump lining materials", Wear, vol. 210, 211-219, 1997. 

AND ITS CONNECTOR BLOCK

17. Masayuki, T., Norio, K., Shozaburo, S., and Siro, M., "Hydraulic Conveying of Solids through Pipe Bends", J. of Chemical Engineering of Japan, vol. 5, No. 1, pp. 4-13, 1972.

18. Mills, D. and Mason, J.S., "Conveying velocity effects in bend erosion”, J. Pipelines, vol. 1, pp. 9-81, 1981.

19. Mishra, A. and Finnie, I., "On the size effect in abrasive and erosive wear", Wear, vol. 65, pp. 359-373, 1981.

20. Neilson, J. H. and Gilchrist, A., "An analytical and experimental investigation of the velocities of particles entrained by the gas flow in nozzles", J. of Fluid Mech., vol. 33, pp. 131-149, 1968.

21. Roco, M.C. and Cader, T., "Energy approach for wear distribution in slurry pipelines", Jap. Journal of Multiphase Flow, vol. 4, pp. 2-20, 1990.

22. Roco, M.C and Minani, L.K., "Effect of particle size distribution and gravitation on wear in centrifugal pump castings", ASME Paper No. 89-FE8, 1989.

23. Shook, C.A. and Roco, M.C., Slurry Flow, Publ. Butterworth-Heinemann, 1991.

24. Singh, T., Tiwari, N., and Sundararajan, G., "Room temperature erosion behaviour of 304, 316, and 410 stainless steels", Wear, vol. 145, pp. 77-100, 1991.

25. Smith H.D. and Elmore, M.R., "Corrosion studies of carbon steel under impinging jets of simulated slurries of neutralized current acid waste (NCAW) and neutralized cladding removal waste (NCRW)", Battelle Pacific Northwest National Laboratory Report No. PNL-7816 (also UC-721), January 1992.

26. Zhong, Y. and Minemura, K., "Measurement of erosion due to particle impingement and numerical prediction of wear in pump casing", Wear, vol. 199, pp. 36-44, 1996.

27. Kay, J. M. and Nedderman, R. M., Fluid Mechanics and Transfer Processes, Cambridge University Press, Cambridge, 1985.

28. Ting, K. and Ma, Y. P., The Evaluation of Erosion/Corrosion Problems of Carbon Steel Piping in Taiwan PWR Nuclear Power Plant", Nuclear Engineering and Design, vol. 191, pp. 231-243, 1999.

29. W. M. Kays and M. E. Crawford, Convective Heat and Mass Transfer, Second Edition, McGraw-Hill Book Company, New York, 1980.

30. Humphrey, J. A. C., "Fundamentals of Fluid Motion in Erosion by Solid Particle Impact", Int. J. of Heat and Fluid Flow, vol. 11, No. 3, pp. 170-195, 1990.

31. Newitt, D. M., Richardson, J. F., Abbott, M., and Turtle, R. B., "Hydraulic Conveying of Solids in Horizontal Pipes", Tans. Instn Chem. Engineers, vol. 33, pp. 93-113, 1955.

32. Lee, S. Y. and Dimenna, R. A., "Validation Analysis for the Calculation of a Turbulent Free Jet in water Using CFDS-FLOW3D and FLUENT (U)", WSRC-TR-95-0170, May 1995.

33. H. Schlichting, Boundary Layer Theory, McGraw-Hill Book Company, New York, 1967. 
WESTINGHOUSE SAVANNAH RIVER COMPANY

EROSION ANALYSIS FOR THE MISALIGNED U2 NOZZLE AND ITS CONNECTOR BLOCK

34. W. M. Rohsenow and H. Y. Choi, Heat, Mass, and Momentum Transfer, PrenticeHall, Inc., New Jersey, 1961.
Report: WSRC-TR-2002-00352

Date:

$10 / 21 / 02$ 55 of 56 
Report: WSRC-TR-2002-00352

Date: $\quad 10 / 21 / 02$

Page: 56 of 56
WESTINGHOUSE SAVANNAH RIVER COMPANY

EROSION ANALYSIS FOR THE MISALIGNED U2 NOZZLE AND ITS CONNECTOR BLOCK

(This Page Intentionally Left Blank) 